\title{
An Overview: Laser-Based Additive Manufacturing for High Temperature Tribology
}

\begin{abstract}
Naveed Ur Rahman ${ }^{1 *}$, David Thomas Allan Matthews ${ }^{1,2}$, Matthijn de Rooij ${ }^{3}$, Amir Mahyar Khorasani ${ }^{1,4}$, Ian Gibson ${ }^{4,5,6}$, Laura Cordova ${ }^{7}$ and Gert-willem Römer ${ }^{1}$

${ }^{1}$ Chair of Laser Processing, Department of Mechanics of Solids, Surfaces and Systems, Faculty of Engineering Technology, University of Twente, Enschede, Netherlands, ${ }^{2}$ Chair of Skin Tribology, Department of Mechanics of Solids, Surfaces and Systems, Faculty of Engineering Technology, University of Twente, Enschede, Netherlands, ${ }^{3}$ Chair of Surface Technology \& Tribology, Department of Mechanics of Solids, Surfaces and Systems, Faculty of Engineering Technology, University of Twente, Enschede, Netherlands, ${ }^{4}$ School of Engineering, Deakin University, Waurn Ponds, VIC, Australia, ${ }^{5}$ Fraunhofer Project Centre for Advanced Manufacturing Technologies and Solutions, University of Twente, Enschede, Netherlands, ${ }^{6}$ Department of Design, Production and Management, Faculty of Engineering Technology, University of Twente, Enschede, Netherlands, ${ }^{7}$ Chair of Dynamics Based Maintenance, Department of Mechanics of Solids, Surfaces and Systems, Faculty of Engineering Technology, University of Twente, Enschede, Netherlands
\end{abstract}

Laser-based additive manufacturing (LBAM) is a versatile manufacturing technique, extensively adopted to fabricate metallic components of enhanced properties. The current review paper provides a critical assessment of the fabricated metallic coatings and parts through LBAM-processes [e.g., laser metal deposition (LMD) and selective laser melting (SLM)] for high temperature tribological applications. A succinct comparison of LBAM-fabrication and conventional manufacturing is given. The review provides an insight into the sophisticated application-driven material design for high temperature tribological contacts. The review highlights the major mechanisms behind the improvement in the tribology of the laser-deposits; properties evolving as a consequence of the microstructure, lamellar solid lubricants, sulfides, soft metals, lubricious oxides, and self-lubricating surfaces.

Keywords: laser-based additive manufacturing, high temperature tribology, solid lubricants, materials design, self-lubricating materials

\section{INTRODUCTION}

In the age of rapid technological advancements in engineering sectors, the production systems are continuously evolving to meet the complex challenges of the present day. Such advancements are raising the robustness, quality and performance barriers of the production systems and of the products due that have to operate under extreme conditions. Among the extreme operating conditions, high temperature environments are considered the most critical in industries as metal forming, aerospace, advanced automotive and power generation to name a few (Rahman et al., 2018). Depending upon the applications, the operating temperature of a given manufactured part may range up to $500^{\circ} \mathrm{C}$ and in some cases up to $1,000^{\circ} \mathrm{C}$. These elevated temperatures (often coupled with thermal fatigue) can have detrimental effects not only on the mechanical properties of the materials but also their surface morphology. This in turn can affect the friction, wear and lubrication characteristics of materials (Semenov, 1995). The harsh operating conditions and complexity of the mechano-chemical processes involved offer a great challenge from the perspective of material design, manufacturing and surface engineering of the industrial production systems and the products. 
High temperature tribological processes are extremely complex in nature due to simultaneous interaction of multiple variables involving; thermal softening, surface morphological changes due to oxidation and diffusion, and surface degradation due to thermo-mechanical fatigue and wear (Hardell et al., 2015). Material design and development for high temperature tribological contacts therefore involves the integration of complex chemical compositions with the addition of lubrication media, in order to achieve optimal hardness, toughness, thermal stability, friction and wear (Matthews et al., 2007). Conventionally, thin (few microns thick) wear resistant coatings are produced by thermally activated chemical vapor deposition (CVD), plasma assisted physical vapor deposition (PA-PVD) and pulsed laser deposition (PLD) techniques to improve the tribological performance for various high temperature applications (Mayrhofer et al., 2006). However, the current industrial production focus is not only to address the extreme temperature environments, but also to enhance the product service life alongside taking into account the economic and environmental aspects in single-step processes. This requires development of new materials with enhanced properties and the utilization of advanced and intelligent production techniques (Singh et al., 2017).

Laser-based additive manufacturing (LBAM) is a family of advanced production systems, use to fabricate metal parts, complete functional and functionally graded products (Li et al., 2017; Loh et al., 2018; Ocelík and De Hosson, 2018), see Figure 1. LBAM has revolutionized the manufacturing industry; from concept development to innovative production of applicationspecific optimized designs (Herzog et al., 2016; Bandyopadhyay and Traxel, 2018; DebRoy et al., 2018). In LBAM, production is carried out by a powder blown system; laser metal deposition (LMD) (Thompson et al., 2015) and laser engineered net shaping (LENS) (Dobbelstein et al., 2018), powder bed fusion system; selective laser melting (SLM) (Zhou Y. H. et al., 2018), and wirefeed system; wire-laser additive manufacturing (WLAM) (Ding et al., 2015). In the powder blown systems, the powder is injected into the laser induced melt pool by a single or multiple nozzles. SLM is a powder bed fusion system, whereby the powder bed is exposed to a single or multiple high energy laser beams, to produce complex parts layer by layer (Parry et al., 2016). In the wire-feed systems (WLAM), wire is used instead of powder to produce the metal components and a laser beam is used as the energy source (Ding et al., 2015). Figure 1 provides an overview of LBAM production systems.

In LBAM, the production is either limited to the development of thin or thick coatings on a substrate (LMD) or manufacturing a full functional metallic product (SLM). In all cases, production through LBAM requires optimization of set of the processing parameters, to avoid defects, such as porosity, pin-hole voids, unmelted powder, micro-cracks and high dilution with the substrate. The primary parameters are laser power, laser scan speed, powder mass flow rate and track overlap or hatch spacing (Yap et al., 2015). LBAM provides freedom of process optimization through on-line process monitoring and in-line quality control. Due to viability of improved mechanical properties, convenience in fabricating intricate products with limited distortion of the product and substrate, strong metallurgical bonding with the substrate, limited HAZ and dilution, LBAM is considered a highly preferable production method over conventional means (Birger et al., 2011; Gibson et al., 2015).

For environmental protection and reduction in $\mathrm{CO}_{2}$ emission, industrial coating applications like hard chrome plating requires replacement and for that purpose thermal spraying and LMD are the potential candidates (Schopphoven et al., 2016). However, LMD is a far better establish industrial application option than thermal spraying as thermal spraying exhibits poor mechanical bonding with the substrate with the porosity up to $1-2 \%$ and is difficult to repair (Schopphoven et al., 2016). Irrespective of the material, due to rapid solidification during LBAM processes, the resulting microstructure is usually fine grain. Cooling rates are faster in the powder bed fusion system compared to those of powder blown systems. LBAM leads to the formation of metastable microstructures and non-equilibrium compositions of the resulting phases (Herzog et al., 2016). Trosch et al. (2016) provide a comparison between the microstructures and associated grain sizes of Ni based super alloy (IN 718) produced by SLM, casting and forging. SLM fabrication provided a highly refined compared to the rest. LBAM coupled with CAD-CAM systems has the ability of producing complex shapes in a single production process. This reduces the number of stages within the production cycle, such as turning, milling, drilling and tooling which results in low investment for machinery systems and manpower (Murr et al., 2009; Wang and $\mathrm{Ku}, 2009$ ). Table 1 lists the advantages of the LBAM processes over established conventional production methods and also lists the current and future challenges to its wider adoption and the further development.

Under vacuum or extreme temperature conditions, the use of liquid lubricants (oils and greases) is not always possible or desired. As an alternative, solid lubricants and selflubricating materials can be utilized to modify the friction and wear in temperature-specific environments (high or cryogenic temperatures) (Donnet and Erdemir, 2004). Solid lubricants are solid materials having low shear strength (Holmberg and Matthews, 2009), and can be added to bulk materials or coatings to lower the friction and wear of the tribological contacts. Alexeyev and Jahanmir (1993) describe the working mechanism of the solid lubricants. An important factor is that solid lubricants deform during sliding and squeeze outward to the counter surface forming a soft interfacial film. Scharf and Prasad (2013) also state that tribological contacts in the presence of solid lubricants, results in the transfer of a thin tribo-film to the counter surface.

In order to enhance the service life of the lubricated contacts, continuous provision of solid lubricants is required. It is essential to maintain an equal percentage of the solid lubricants throughout the service life of the composite materials to exhibit a consistent tribological performance. In the case that one of the contact partners is continuously replaced, like in manufacturing, the use of embedded solid lubricant therefore lead to depletion of the material which contains solid lubricants. Also, in order to maintain a thin film on the surface, generation and supply of the soft phase should balance the consumption of soft phase in the 


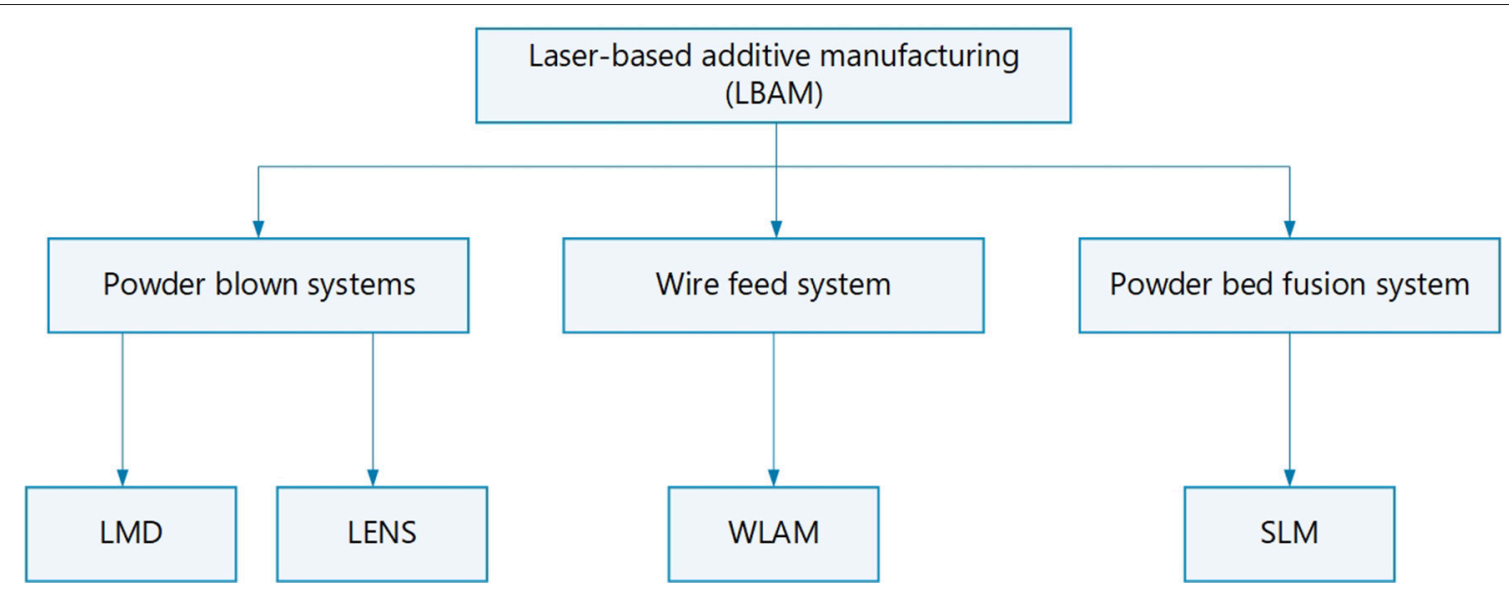

FIGURE 1 | LBAM production systems; categorized into powder blown, wire feed and powder bed fusion systems.

TABLE 1 | Advantages and challenges of LBAM processes (Donnet and Erdemir, 2004).

Advantages

- Customization of the product and economically attractive compared to mass production

- Direct production from 3D CAD model

- 3D CAD model for production are easily shareable leading to further customization

- Recycling of the powder material gives rise to reuse of the waste and material saving

- Novel material processing, intricate structures, such as free-form enclosed structures and channels, and lattices are achievable

- Low porosity of the final product

- Overcoming the risk of inventory

- Direct interaction between consumer and producer
Current and future challenges

- Cost and speed of production

- Perception of additive manufacturing to be used for rapid prototyping instead of direct production

- Standardization of products

- Validation of LBAM products thermal and mechanical properties

- Development of multi material system

- Automation of LBAM processes to enhance the process and production efficiency

- Intellectual property and copy right issues

- Limited trained manpower in LBAM processes contact (Song et al., 2010). For example in hot rolling, in case of spun cast work roll of indefinite chilled double pour (ICDP) iron material, free graphite present in the microstructure acts as a solid lubricant. Due to intrinsic limitations of the casting process, the percentage fraction of graphite across the work roll shell radius is not homogenously distributed (Luc et al., 2015). As a result the wear performance and mechanical strength are affected. Due to production limitations of conventional processes, LBAM becomes an attractive manufacturing technology, ensuring the homogenous distribution of alloying constituents by precisely tailoring the processing conditions. In LBAM, a variety of solid lubricants can be mixed with the base materials in the form of powders; hence providing freedom to develop applicationspecific materials (Torres et al., 2017).

A generic classification of the solid lubricants is shown in Figure 2 (left) (Furlan et al., 2018). A production flow diagram is also shown in Figure 2 (right), describing an advanced application-specific production approach based on design of materials with or without addition of solid lubricants, with the utilization of LBAM for high temperature tribological processes.
Quazi et al. (2016) state that solid lubricants, used in additive manufacturing, can be classified in three groups. The first group consists of lamellar structured materials, graphite, transition metal dichalcogenides (TMDs) compounds $\left(\mathrm{MoS}_{2}\right.$ and $\left.\mathrm{WS}_{2}\right)$ and hexagonal boron nitride $(\mathrm{hBN})$. The second group covers soft metals (e.g., $\mathrm{Ag}, \mathrm{Cu}$, and $\mathrm{Sn}$ ) while the third group is comprised of metal-oxide-fluorides (e.g., $\mathrm{CaF}_{2}$ and $\mathrm{BaF}_{2}$ ). At elevated temperatures (above $500^{\circ} \mathrm{C}$ ) lamellar-structure and soft metal based solid lubricants become ineffective due to their thermal decomposition, structural degradation and oxidation. Erdemir (2000) describes the lubricious aspect of the metaloxides and metalloids at high temperatures. In the metal forming industry, characteristics of the metal-oxides are found to be either abrasive or lubricious. Magnetite $\left(\mathrm{Fe}_{3} \mathrm{O}_{4}\right)$, molybdenum oxide $\left(\mathrm{MoO}_{3}\right)$, vanadium oxide $\left(\mathrm{V}_{2} \mathrm{O}_{5}\right)$, and tungsten oxide $\left(\mathrm{WO}_{3}\right)$ are considered as lubricious oxides with weak cohesive bonds (Dohda et al., 2015).

The current paper is focused to provide a comprehensive review of the available literature for the design of materials for high temperature tribological applications, while considering the 


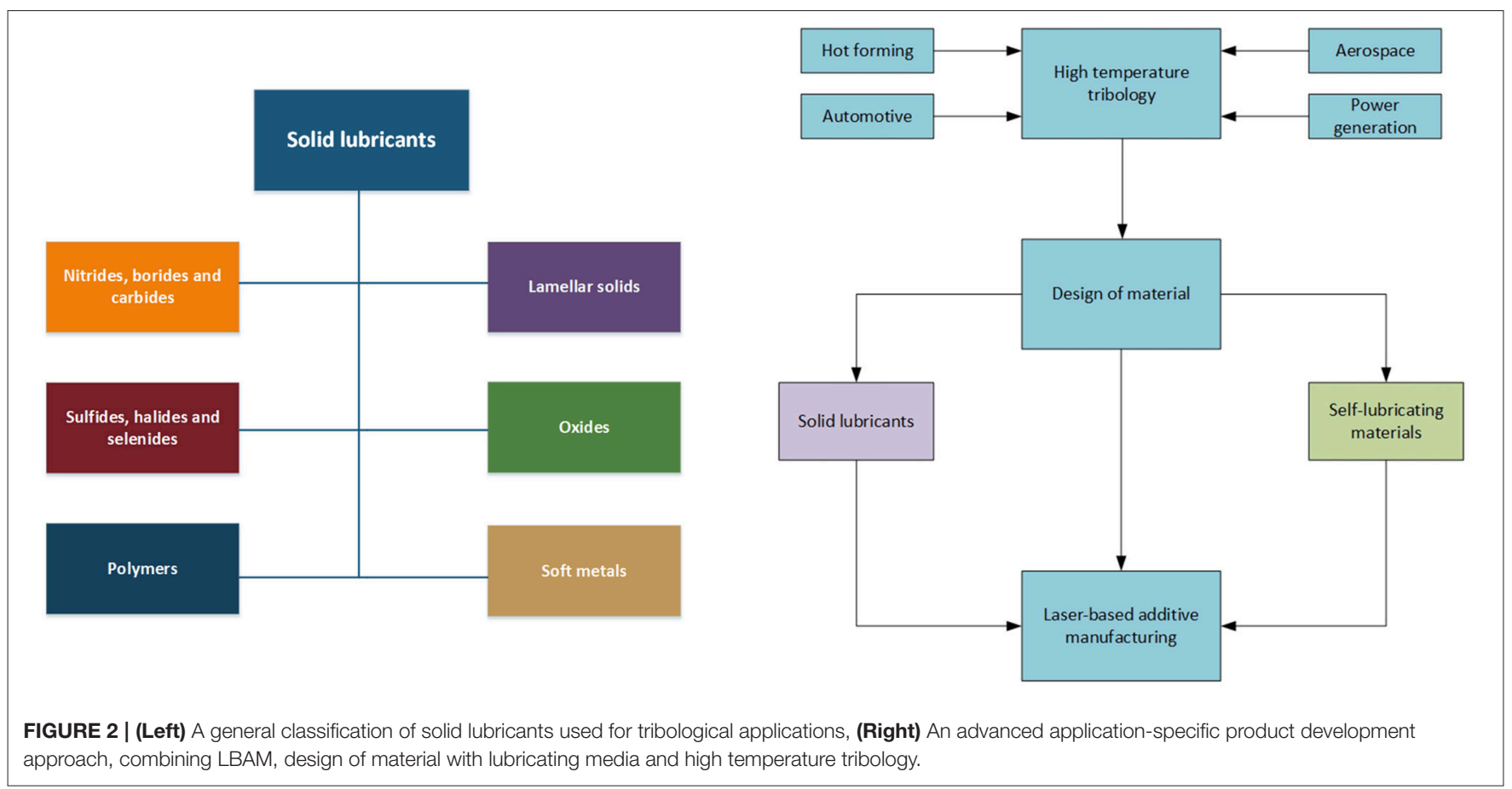

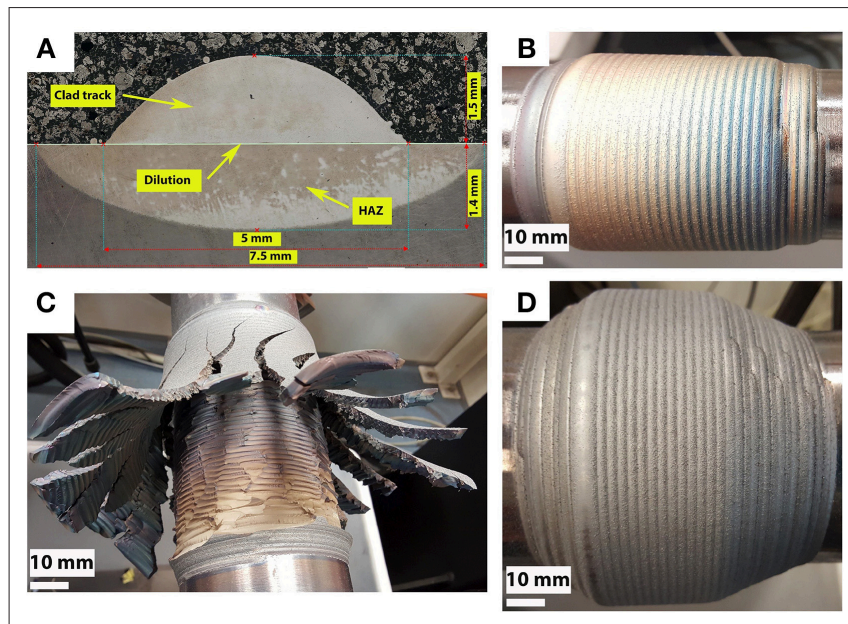

FIGURE 3 | (A) Optical image of the cross-section of laser clad, showing, clad region, minimal dilution with the substrate and heat affected zone (HAZ), (B) Double layer image of the defect free LMD, (C) Hot-cracking of the laser deposits due to high thermal residual stresses, and (D) Fabrication of $20 \mathrm{~mm}$ thick HSS coatings for hot metal forming production systems [reprinted from Ur Rahman et al. (2018).

incorporation of lubricating phase, followed by manufacturing through LBAM production systems. High temperature tribological characteristics of such fabricated coatings and products are discussed. In order to enhance the clarity of the paper, specific applications are addressed with a focus on the metal forming industry (hot rolling, hot stamping, molding and forging) in section Metal Forming, while advanced automotive (engine), aerospace and power generation (nuclear energy) applications are addressed in section Aerospace, Automotive, and Power Generation. Emerging materials, which are promising candidates for new applications are addressed in section Emerging Materials.

\section{METAL FORMING}

In the metal forming industry, components (e.g., work rolls, tools, molds, and dies) are subjected to extremely high thermal (up to $1,200^{\circ} \mathrm{C}$ in hot extrusion) and mechanical $(>1.0 \mathrm{GPa})$ dynamic loads, which result in wear, fatigue and plastic deformation (Kashani et al., 2007; Birol, 2010). The hot metal forming operations involve multiple transient thermal cycles of varying time durations, which inflict a great challenge to the integrity of the tool and product in terms of dimensional stability and surface finish. Wan et al. (2016) consider surface lubrication as the prime area of optimization in the metal forming for quality production and robustness of the production system.

In the extreme working conditions, simultaneous interactions of various wear mechanisms determine the wear behavior of metal forming components (MFCs). The wear mechanisms are abrasion, adhesion, tribo-oxidation and surface fatigue (Ilo et al., 2011). During the contact with the product, the MFCs surface often heats up from room temperature to 500$600^{\circ} \mathrm{C}$ (due to conduction, deformation and friction) and is subsequently cooled down by a water spray (Colás et al., 1999). The cyclic fatigue due to thermal and mechanical loads promotes compressive stresses during heating, and tensile stresses upon cooling, resulting in degradation of the MFC surface (Fedorciuc-Onisa and Farrugia, 2008; GarzaMontes-de-Oca et al., 2011; Deng et al., 2017). In addition, MFCs also suffer abrasive and oxidative wear. Such wear 
is the result of a high compressive loads and the slip between the MFCs and the product (Belzunce et al., 2004). The presence of a hard iron oxide layer $(\approx 1,000 \mathrm{HV})$ on the counter surface continuously abrades the MFCs (GarzaMontes-de-Oca and Rainforth, 2009). MFCs also experience sticking and micro-welding with the product and such adhesion results in surface defects both on the MFCs and the product (Wei et al., 2011).

The tribological behavior of the MFCs has a strong influence on the surface quality of the product and also the life of the MFC. Improving the performance and service life of the MFCs is an important subject for the manufacturer and the metal forming industry, because the MFCs are responsible for the $15 \%$ of the overall production cost (Boccalini and Sinatori, 2002). In metal forming industry, the most versatile MFC material is high speed steel due to excellent mechanical properties at high temperatures (Pellizzari et al., 2005, 2009; Aqida et al., 2013). The conventional production of the MFCs is performed by casting, which imposes production limitation on the microstructure and the mechanical properties. That is, slow cooling rates in the casting process results in coarse grain structures and such a microstructure is not effective to the (thermo-mechanical) fatigue stresses to which the MFCs are exposed in the metal forming industry. In the casting process, there is limited freedom on the selection of the shell alloy composition due to compatibility issues of shell-core and also due to segregation of coarse grain boundary carbides.

To overcome the production limitations and to meet the challenges of the metal forming production environment, LBAM offers fabrication and product performance advantages (Nilsson and Olsson, 2013a,b). Due to high cooling rates of LBAM, the microstructure can be much more refined, with higher average matrix-carbides hardness (Sun et al., 2018). Concentrating on LMD, literature shows there to be many possible coating materials for high temperature applications; for example Fe-based alloys, metal silicides, carbides and borides, stellites, superalloys (e.g., Ni- or Co-based) and self-lubricating materials (Leunda et al., 2011; Tuominen et al., 2016; Yao et al., 2018). The conventional processing of these costly alloys is difficult. In most of the cases, laser deposition of these alloys is performed on less expensive low alloy steel substrates. These alloys are reported to exhibit good cladability with low alloy steel substrates (Wang et al., 2006).

By utilizing the $4.0 \mathrm{~kW}$ Nd:YAG laser source, a $20 \mathrm{~mm}$ thick coatings of high speed steel (HSS) alloy was successfully laser deposited on a $100 \mathrm{~mm}$ diameter $42 \mathrm{CrMo}_{4}$ substrate for fabrication of MFCs (Ur Rahman et al., 2018). See also Figure 3 provides an overview of surface layers developed for and by LBAM. The Figure highlights the layer thicknesses attainable (A), a double layer (B), the limitations - for example the disastrous effect of high thermal residual stresses (C) and the possibilities of the LBAM process to realise $20 \mathrm{~mm}$ thick tool steel builds (D). The microstructures of the LMD HSS alloys were highly refined with approximate average micro-hardness of $800 \mathrm{HV}$, are suitable to resist the cyclic thermo-mechanical fatigue (Cong et al., 2018). Figure 4 shows the SEM micrograph of the LMD HSS alloy along with the EDS analysis. The micrographs show the homogenous distribution of the carbides along the grain boundaries and also the presence of nanometer sized carbides within the matrix (Ur Rahman et al., 2019a). The comparative tribological performance of the HSS coatings were tested by using high temperature pin-on-disc tribometer. At room temperature, the LMD HSS coatings showed exceptional tribological performance due to higher micro-hardness when compared to that of cast HSS. At $500^{\circ} \mathrm{C}$, the friction and wear were heavily influenced by the microstructural features and oxidation kinetics of laser deposited materials (Hashemi et al., 2017; Ur Rahman et al., 2019a). Figure 5 shows the SEM micrograph of the worn surfaces HSS alloys tested at $500^{\circ} \mathrm{C}$. The wear mechanism was found to be the combination of abrasive, adhesive and oxidative wear. Carbide particles were removed during the wear process and metal-oxidecarbide debris were redeposited on the worn surfaces.

In the hot strip mill (HSM), alignment of the rolled material is performed by guiding plates, also known as wear plates. The life time of the guiding plates is limited due to extreme conditions of

the HSM, requiring frequent maintenance. Torres et al. (2016a,b) performed high temperature tribological studies (up to $700^{\circ} \mathrm{C}$ ) to find the potential substitution for the reference steel 1.0050. High temperature sliding wear testing was performed on the reference material and three substitute materials gray cast iron, abrasion resistant martensitic grade and Fe-Cr-V hard facing material, where the latter was deposited by LMD. It was found that LMD Fe-Cr-V alloy showed the least wear during the entire temperature range. The lowest wear was attributed due to retention of high hardness at elevated temperatures.

Kazadi et al. (2006) show the potential of using LMD to repair general steel mill components. Specifically they apply LMD coatings to foot rolls of two dimensions (substrate = ST55), descaler cassettes (ST50), foot roll shafts (ST50-2), distance sleeves (ST35) and idler rolls (ST50-2). They performed highspeed laser cladding (processing speed $\approx 3 \mathrm{~m} / \mathrm{min}$ ), to avoid excessive heat input and consequential work piece distortion. Several coatings are used, consisting of $316 \mathrm{~L}$ austenitic stainless steel (distance sleeve and foot roll shaft), 431 martensitic stainless steel (foot roll $630 \mathrm{~mm}$ and Idler sleeve), $60 \mathrm{~S}$ (descaler cassette) and Diamalloy 1008 (foot roll 300). Unfortunately little or no information is given as regards in-service performance.

Lester et al. (2013) conducted comparative room temperature and high temperature $\left(\right.$ at $\left.700^{\circ} \mathrm{C}\right)$ sliding wear tests for the evaluation of tribological performance of laser fabricated and conventionally manufactured alloys for continuous caster rolls used in the compact strip production (CSP). Room temperature tests were performed for LMD WC and high carbon alloy cast roll steel. It was found that LMD WC showed an excellent wear resistance than cast alloy. For high temperature $\left(\right.$ at $\left.700^{\circ} \mathrm{C}\right)$ tribological tests, LMD Stellite 6 outperformed submerged arc clad martensitic stainless steel.

Ur Rahman et al. (2019b) laser fabricated V-rich HSS alloy by varying the laser processing speed and compared the high temperature friction and wear performance with reference to the cast alloy. Laser processing of V-rich HSS alloy at various laser scan speeds modified the morphology of the VC carbides which play essential part during the wear process. SEM micrographs of the microstructures show that morphology of the VC carbides changes from square and round shape to angular and rod shape, 

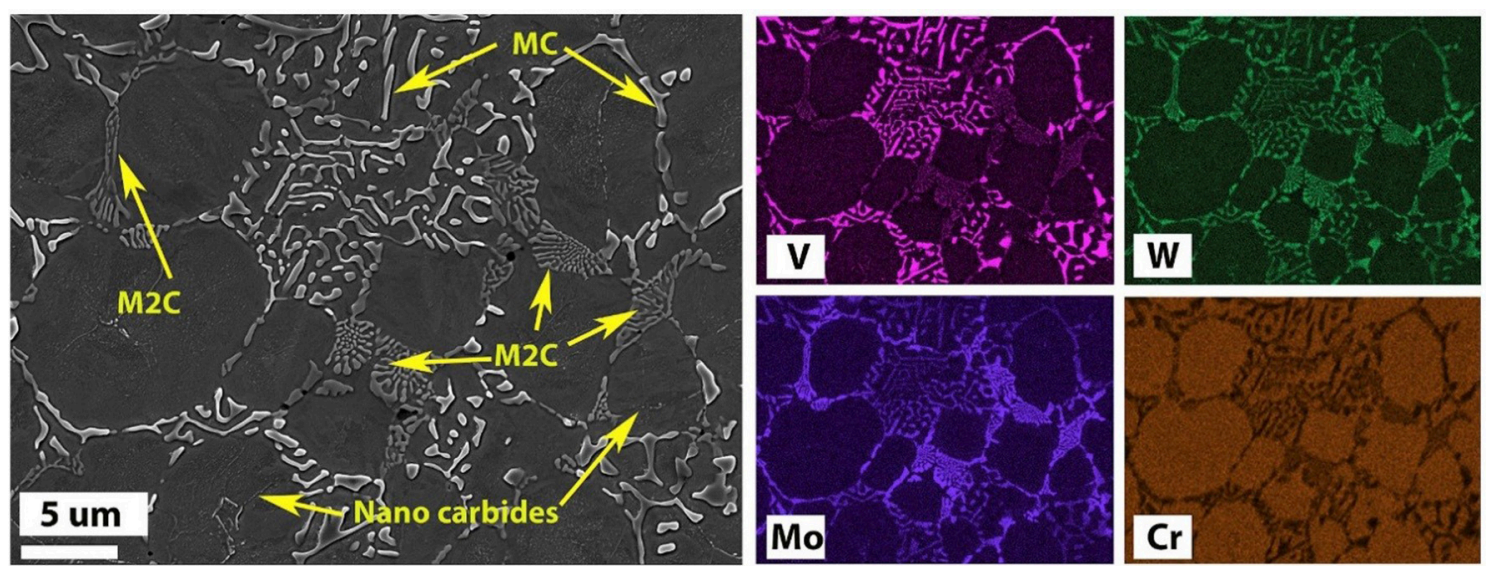

FIGURE 4 | (Left) SEM micrograph of laser fabricated high speed steel alloy showing the homogenous presence of the microstructural features; martensitic matrix and the carbides, (Right) EDS images showing the distribution of various carbide forming elements in the presented SEM micrograph on left [reprinted from Ur Rahman et al. (2019a) with permission from Elsevier, license number 4533690669938].
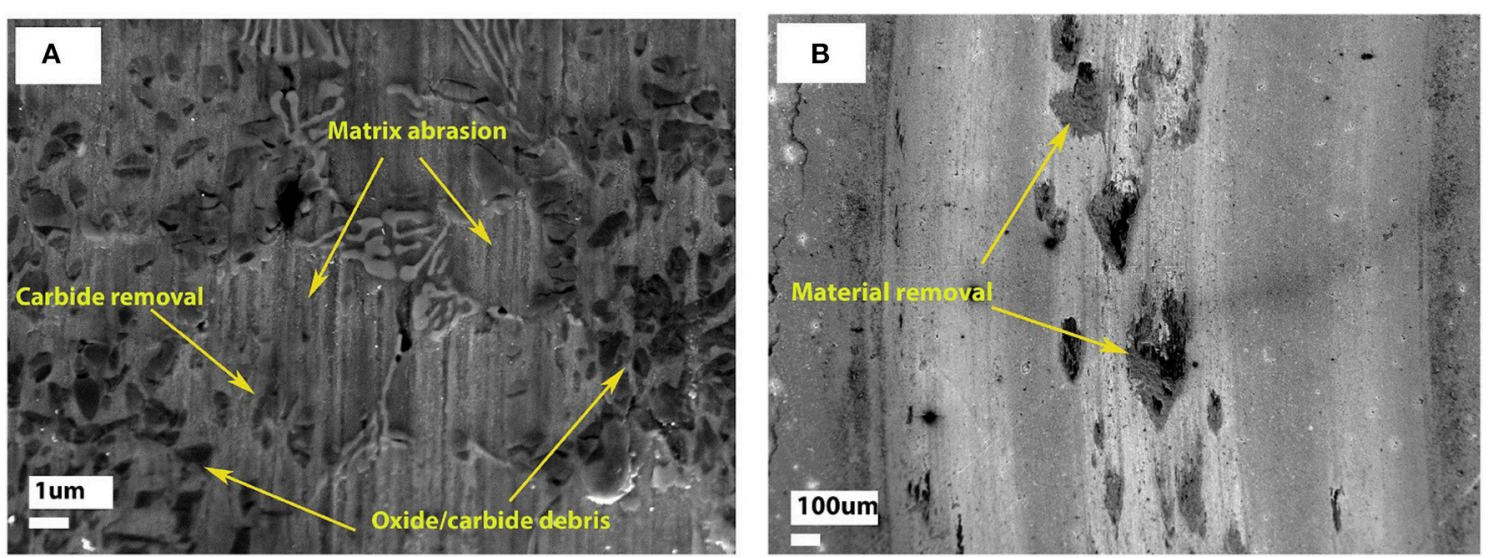

FIGURE 5 | (A) SEM micrograph of the worn surface of LMD high speed steel alloy tested at $500^{\circ} \mathrm{C}$ showing deposition of oxide-carbide debris on the worn surface, (B) Worn surface of the counter material showing removal of material [reprinted from Ur Rahman et al. (2019a) with permission from Elsevier, license number 4534150008459].

see Figures 6A-C relative to the reference cast alloy (Figure 6D). By reducing the size of the carbides below a critical limit reduced their ability to support the counter surface during the wear process, which resulted an increase in wear. It was also reported that improving the morphology of VC carbides by refining the microstructure as in case of V-rich HSS $10 \mathrm{~V}$, resulted in stabilizing the friction profile during wear, see Figure 7.

d'Oliveira et al. (2002) compared the deposition of Stellite 6 (Co-Cr-W-C) by plasma transferred arc (PTA) and LMD on a stainless steel (AISI 304) plate (no substrate pre-heating is mentioned). They (cyclically) soak the coatings after deposition at $1,050^{\circ} \mathrm{C}$ and retest the coating hardness and structural stability. They show that the micro-hardness of the laser deposits drop after exposure to high temperature whereas a micro-hardness stability is reported for PTA coatings. They recommend that hard-faced components for high temperature applications should be processed to realize the stable microstructures. This can be achieved either by appropriate post-heat treatment after LMD or selecting the adequate coating process. This will reduce the modifications of microstructural features, such as carbides morphology, percentage volume fraction, etc., resulting a stable wear behavior at high temperature and reduction in accelerated degradation of surfaces.

Yang (1999) demonstrate the possibility of using a globular Nibased alloy precursor (Ni48.1-W16.4-Al9.8-Co8.5-Cr5.1-Mo4.8Fe4.6+Ti2.7) reinforced with "lumpy" WC particles. They chose a mix of $70 \%$ Ni-based powder and 30\% WC. No information is given with respect to the initial crystallinity of the WC powder employed. As another variant on Ni-based alloys, Wang et al. have published a number of articles on exploring binary and ternary metal-silicide coatings (Duan and Wang, 2002; Wang and Duan, 2002; Cai et al., 2003; Lu and Wang, 2005; Sheng et al., 2008). Sheng et al. (2008) address the microstructure and high temperature wear behavior of 

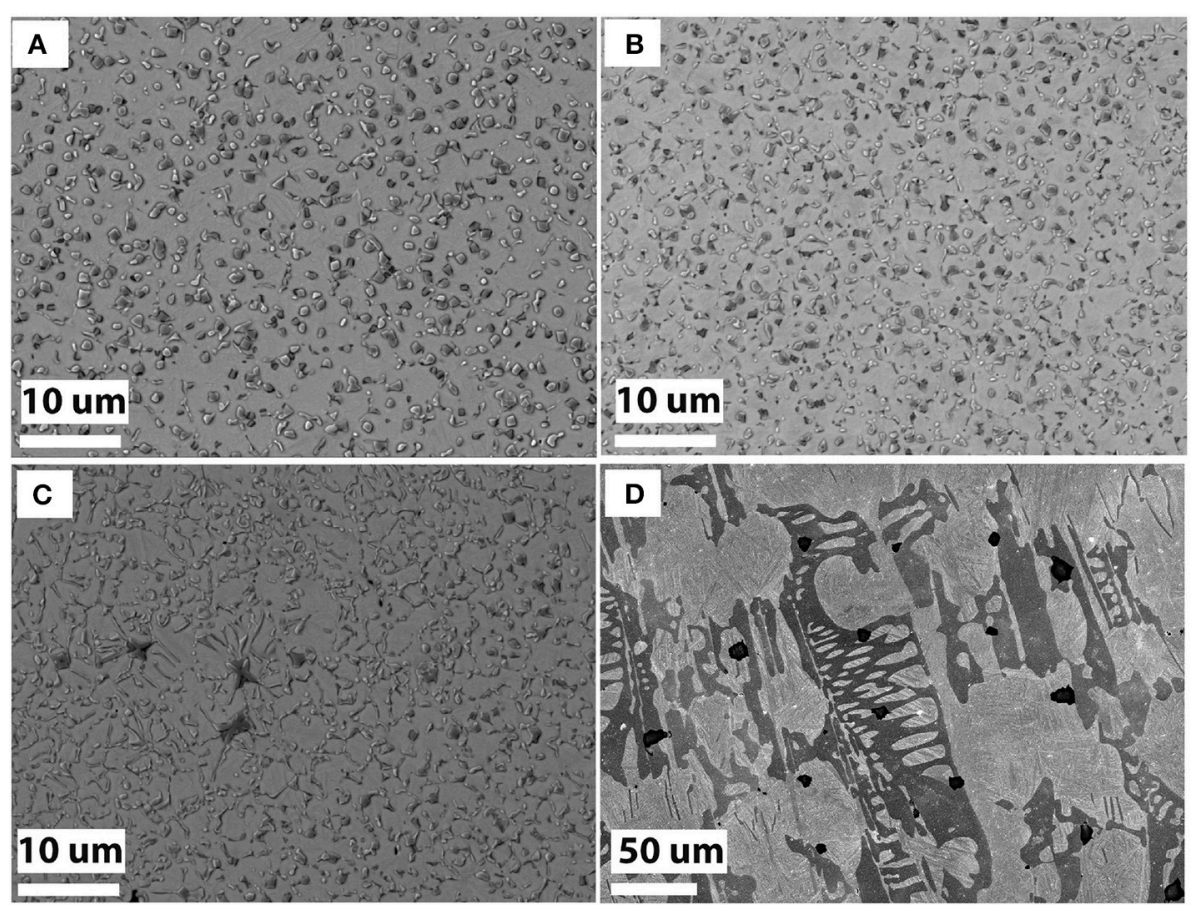

FIGURE 6 | (A-C) SEM micrographs of the V-rich HSS alloy laser fabricated (LMD) at different laser scan speeds, (D) SEM micrograph of the reference cast alloy [reprinted from Ur Rahman et al. (2019b) with permission from Elsevier, license number 4537620780348].
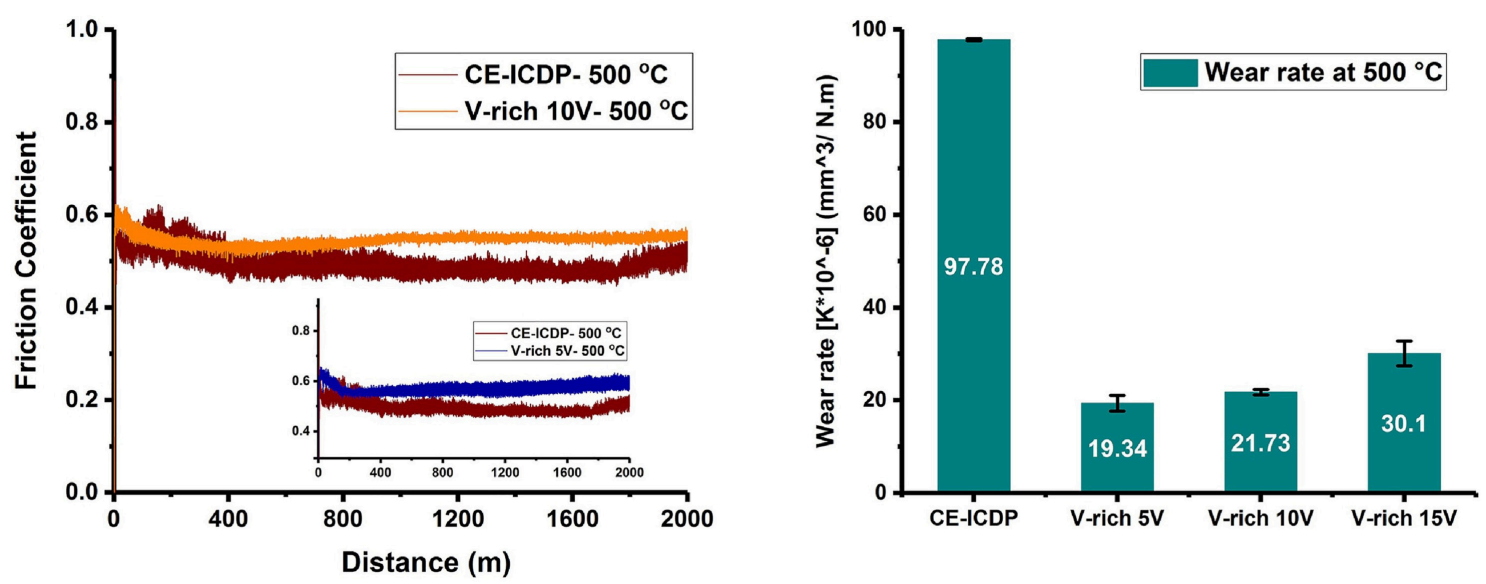

FIGURE 7 | (Left) Friction profiles of V-rich HSS alloy and cast alloy, (Right) Wear rate measurement at $500^{\circ} \mathrm{C}$ showing an increase in wear due to reduction in load bearing capability of VC carbides [reprinted from Ur Rahman et al. (2019b) with permission from Elsevier, license number 4537620780348].

laser deposited Ni-Ti-Si ternary metal-silicide coatings. Due to high micro-hardness and elastic modulus, the metal-silicides generally present good abrasive wear resistance. Ternary metalsilicides are reported to exhibit better wear (abrasive and adhesive) resistance when compared to binary metal-silicides (Alman et al., 1995; Newkirk and Hawk, 2001).

Sheng et al. (2008) used commercially pure $\mathrm{Ni}, \mathrm{Ti}$ and $\mathrm{Si}$ powders (powder particle size of $90-250 \mu \mathrm{m}$ ) in the ratio: $70 \mathrm{Ni}$ 21Ti-9Si (wt.\%) to produce a defect free $2.5 \mathrm{~mm}$ thick coating on stainless steel (AISI 304) substrates. The microstructure was comprised of dendritic $\mathrm{Ni}_{16} \mathrm{Ti}_{6} \mathrm{Si}_{7}$ and Fe-Ni-based $\gamma$ solid solution. The micro-hardness was $\sim 600 \mathrm{HV}(500 \mathrm{~g})$. The coatings were tested under pin-on-disk dry sliding conditions at elevated temperatures $\left(400,500\right.$, and $\left.600^{\circ} \mathrm{C}\right)$ against the nickel based superalloy GH5K. Neither, substrate pre-heating nor coating post-treatment was reported, however at high temperature the Ni-Ti-Si ternary metal silicide coatings showed an excellent wear resistance. High temperature wear resistance was due to the presence of primary covalent atomic bonds and high micro-hardness of the $\mathrm{Ni}_{16} \mathrm{Ti}_{6} \mathrm{Si}_{7}$ ternary metal silicide. 


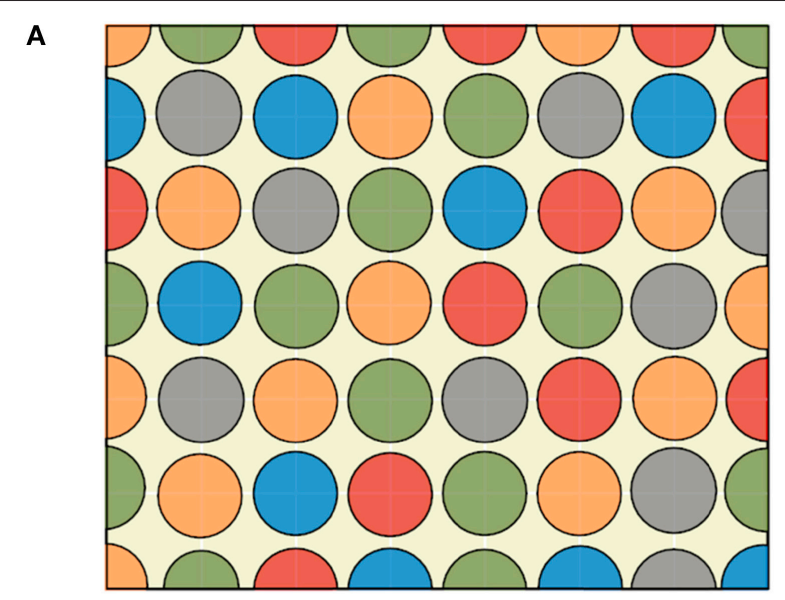

B

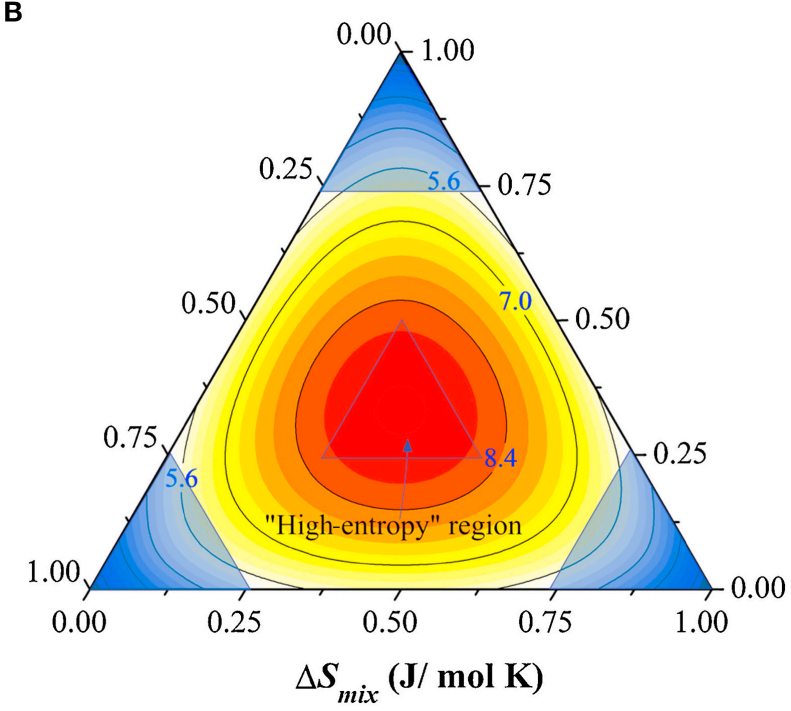

FIGURE 8 | (A) Illustrated concept of alloy mixing for maximum entropy, (B) Schematic of configuration entropy map showing the central region as HEAs with maximum configuration entropy $\left(\Delta S_{\text {mix }} \mathrm{J} / \mathrm{mol} \cdot \mathrm{K}\right)$ [reprinted from $\mathrm{Ye}$ et al. (2016) under Elsevier creative common license].

The fracturing of the primary dendrites resulted in the wear of coatings. The unique microstructure as a result of laser fabrication and a transfer layer were found to form which also has a positive role in the wear process.

Ray et al. (2014) employed LMD to improve the service life of lateral rolls in the zero segment of continuous slab caster. $\mathrm{Ni}$ based powders with the varying additions of $\mathrm{Cr}, \mathrm{Mo}, \mathrm{B}, \mathrm{Nb}$ were deposited. The microstructural characterization revealed the presence of $\mathrm{NiCr}$ dendrites are surrounded by $\mathrm{Cr}$ and $\mathrm{B} / \mathrm{Nb}$ enriched hard phases. Hard precipitates improved the wear resistance. During actual performance evaluation, it was found that in the absence of corrosive environment, rolls with improved wear resistance properties produced maximum service life. The lateral rolls cladded with higher percentage of $\mathrm{Ni}$ and $\mathrm{B}$ were free from cracks and delamination. Two LMD coatings (Stainless steel and $\mathrm{Ni}$ alloy) for continuous casting rolls were tested in work of Sanz (2004) against one overlay welding and two chemically hardened HVOF coatings. The laser metal deposits showed less than half the wear rates when compared to that of new generation welded overlay. The wear (abrasive) resistance of LMD coatings was approximately equal to, or somewhat less than welded martensitic stainless steel. LMD coatings of Ni-based and Fe-based alloys and best welded layer showed a similar abrasive wear resistance.

Duan and Wang (2002) studied $\gamma / \mathrm{Cr}_{3} \mathrm{Si}$ metal-silicide coatings showing high-temperature sliding wear resistance. Austenitic stainless steel was the chosen substrate and commercially pure chromium, silicon and nickel elemental powder blends were used as precursors in the wt.\% ratio of 54.25Cr-15.75Si-30Ni. The resulting coating (developed with pre-placed powders) with the preferential precipitation of $\mathrm{Cr}_{3} \mathrm{Si}$ during solidification as the primary phase. The $\mathrm{Cr}_{3} \mathrm{Si}$ primary phase grows freely in the melt pool as primary dendrites. The residual liquid in the inter-dendritic region is enriched with nickel and depleted in chromium and silicon forming the base $\gamma$-nickel solid solution, resulting in the $\gamma / \mathrm{Cr}_{3} \mathrm{Si}$ metal-silicide composite coating (Wang and Duan, 2002). The micro-hardness (at room temperature) was found to be almost $1,100 \mathrm{HV}$ and showed an excellent wear resistance $(\approx 6$ times better than austenitic stainless steel) at high temperatures $\left(600^{\circ} \mathrm{C}\right)$. $\gamma / \mathrm{Cr}_{3} \mathrm{Si}$ metal-silicide laser clad coatings showed excellent wear resistance at high temperatures due to the presence of oxidation and homogeneously dispersed hard and wear resistant $\mathrm{Cr}_{3} \mathrm{Si}$ primary dendrites.

Laser deposition of reinforced NiSi silicide intermetallics have been presented in Cai et al. (2003) (Cr-alloyed coatings with Vickers hardness $\approx 1,000 \mathrm{HV}$ ) (Wang et al., 2003) $\mathrm{Ni}_{2} \mathrm{Si}$ additions to form coatings of $750 \mathrm{HV}$ micro-hardness and wear resistance (at room temperature) $>5$ times that of its stainless steel substrate) and Lu and Wang (2005) in which $\mathrm{Mo}_{2} \mathrm{Ni}_{3} \mathrm{Si}$ additions result in a coating of $\sim 900 \mathrm{HV}$ which exhibits excellent wear resistance at room temperature, however no high temperature wear testing was presented for either coating system.

Tribaloy (CoMoCrSi alloys) are well-known to exhibit excellent wear and corrosion resistance. Instead of relying on metal carbides for mechanical properties, these alloys gain their strength from the alloying elements like Mo and Si. These alloying elements promote the formation of hard and corrosive resistant microstructure consisting of laves phases (Ya et al., 2018). High temperature wear and corrosion testing of Tribaloy showed that these alloys could be used in mild to high corrosive and/or elevated-temperature environments (Yao et al., 2005, 2006; Tobar et al., 2008).

Tobar et al. (2008) analyzed, laser deposited coatings of CoMoCrSi alloys (Tribaloy-800 and Tribaloy-900) on AISI 304 steel substrate. The defect (porosity and micro cracks) free laser deposits, of about $1 \mathrm{~mm}$ thickness, had strong metallurgical bonding with the substrate. Navas et al. (2006) performed tribological testing of Tribaloy $\mathrm{T}-800$ by using ball-on-disk and block-on-ring configurations. The tribological tests were conducted at room temperature. They show that for Tribaloy T-800 coatings, the wear behavior is not strongly influenced by the presence of laves phases. However, the applied load is 
supported by the laves precipitates homogeneously distributed in the metallic matrix without being removed.

Torres et al. (2018a) worked on the microstructural design of $\mathrm{Ni}$ based self-lubricating coatings with the addition of and $\mathrm{MoS}_{2}$ produced by laser-based additive manufacturing as a first step toward potential use in metal forming. $\mathrm{MoS}_{2}$ is a lamellar structured solid lubricant (Scharf and Prasad, 2013). During sliding, the strong ionic bond between the Mo and $\mathrm{S}$ provides strong resistance to contact load while the crystalline layers of the $\mathrm{MoS}_{2}$ slide easily and reorient parallel to the sliding direction, providing lubrication. Lei et al. (2015) reported that $\mathrm{MoS}_{2}$ was decomposed during LMD. However, Torres et al. stated that addition of $\mathrm{MoS}_{2}$ resulted in the encapsulation of $\mathrm{Ag}$ during the laser processing to ensure its uniform distribution across the laser deposits and prevented it to float in the melt pool. Improved retention of the $\mathrm{Ag}$ was found during addition of $5 \mathrm{wt} . \% \mathrm{Ag}$ and 10 wt. $\% \mathrm{MoS}_{2}$ to $\mathrm{NiCrSiB}$ powder. A high temperature tribological study was carried out at $600^{\circ} \mathrm{C}$ under unidirectional sliding. $\mathrm{MoS}_{2}$ on decomposition formed chromium sulfides which was effective in reducing both friction and wear. Room temperature and high temperature tribological performance was significantly improved compared to reference alloy. No substantive advantage of $\mathrm{Ag}$ addition was reported at high temperature, probably due to oxidation (Torres et al., 2018b).

In another study, Torres et al. (2018c) modified the Ni based coatings with the additions of soft-metal solid-lubricants $\mathrm{Ag}$ and $\mathrm{Cu}$. TMDs $\mathrm{WS}_{2}$ and $\mathrm{MoS}_{2}$ were used for the encapsulation of the soft-metal solid-lubricants due to their decomposition in the melt pool. Tribological behavior was investigated up to $600^{\circ} \mathrm{C}$ under reciprocating sliding conditions. Self-lubricated Ni based coating showed improved tribological performance due to presence of lubricious sulfides.

Liu et al. (2013a) fabricated self-lubricating coatings of $\mathrm{NiCr} / \mathrm{Cr} 3 \mathrm{C}_{2}-\mathrm{WS}_{2}-\mathrm{CaF}_{2}$ mixed powders by $\mathrm{LMD}$ for high temperature tribological applications. Friction and wear characteristics of these laser coatings under different temperatures and loads were studied against $\mathrm{Si}_{3} \mathrm{~N}_{4}$ ceramic counter surface. These coatings exhibited excellent tribological behavior under moderate temperatures and loads.

\section{AEROSPACE, AUTOMOTIVE, AND POWER GENERATION}

Additive manufacturing processes are extensively employed in aerospace, automotive and power generation sectors due to their ability to manufacture geometrically complex parts by substituting several individual machining processes (Sexton et al., 2002). The main advantage of additive manufacture is to fabricate component of advance alloys which are difficult to machine and or would offer serious tooling problems. In these sectors many systems are subjected to high temperature, high stress and vibration effect, leading to erosion and creep (Kathuria, 2000; Kaierle et al., 2017). A few examples of these are engine bearings, cylindrical liners, valves, gas/steam turbine blades, bearing rings, casings, bearing and bushings for space satellites, rocket nozzles, hypersonic aircrafts and missiles, nuclear and chemical vessels. Aggressive operating conditions require novel high performance wear resistant alloys with self-lubricating characteristics (Zhu et al., 2013). Ti alloys and Ni based super alloys are extensively used under such conditions to ensure the high reliability and surface integrity (Pusavec et al., 2011; Rynio et al., 2014). As an example, in the gas turbine engine, compressor stages, combustion chamber, and the turbines stages of the gas turbine engine are produced from $\mathrm{Ti}$ and $\mathrm{Ni}$ alloys (Ulutan and Ozel, 2011).

Ti-based alloys are corrosion resistive and biocompatible, also possess a high strength to weight ratio with low elastic modulus and density (Liu et al., 2014; Khorasani et al., 2015). These are widely used in biomedical, power generation and aerospace industries (Yamada, 1996; Brandl et al., 2010). However, due to poor high temperature tribological characteristics (high and unstable coefficient of friction and lower abrasive and adhesive wear resistance) and low micro-hardness, the use of these alloys is limited ( $\mathrm{Li}$ et al., 2012, 2015). There is an increasing intent on enhancing the surface properties of $\mathrm{Ti}$ alloys in general by utilizing the LBAM processes (Szost et al., 2016). In different trials self-lubricating composite coatings were deposited on $\mathrm{Ti}$ alloys by using LMD and such additions on Ti alloys resulted in friction reduction and improved anti-wear characteristics (Candel et al., 2010; Feng et al., 2012; Weng et al., 2015; Zhai et al., 2017). However, powder is preplaced on the substrate, rather than being injected in the laser-induced melt pool, in most of the mentioned applications.

Ocelík et al. (2005) deposited metal-matrix composite layer of $\mathrm{TiB} / \mathrm{Ti}-6 \mathrm{Al}-4 \mathrm{~V}$ on $\mathrm{Ti}-6 \mathrm{Al}-4 \mathrm{~V}$ substrates by LMD. Laser metal deposits consisted of two distinct microstructures, primary and eutectic $\mathrm{TiB}$ particles dispersed in the matrix of $\mathrm{Ti}-6 \mathrm{Al}-4 \mathrm{~V}$. The sliding wear tests were performed under boundary lubrication conditions at a low constant sliding speed of $0.01 \mathrm{~m} / \mathrm{s}$ and at contact pressures of 20 and $100 \mathrm{MPa}$. The metal-matrix composite layer of $\mathrm{TiB} / \mathrm{Ti}-6 \mathrm{Al}-4 \mathrm{~V}$ showed outstanding wear resistance and friction improvement. The deposited layer was strongly adhered due to excellent interfacial bonding between the $\mathrm{Ti}-6 \mathrm{Al}-4 \mathrm{~V}$ matrix and the in situ TiB. At $20 \mathrm{MPa}$, $\mathrm{TiB} 2 / \mathrm{Ti}-6 \mathrm{Al}-4 \mathrm{~V}$ performed best, while at $100 \mathrm{MPa}$ the eutectic microstructure of $\mathrm{TiB} / \mathrm{Ti}-6 \mathrm{Al}-4 \mathrm{~V}$ showed good wear resistance.

Liu et al. (2014) produced defect free novel coatings of $\gamma$-NiCrAlTi/TiC $+\mathrm{TiWC}_{2} / \mathrm{CrS}+\mathrm{Ti}_{2} \mathrm{CS}$ on $\mathrm{Ti} 6 \mathrm{Al} 4 \mathrm{~V}$ alloy substrate. The coatings were produced by preplaced $\mathrm{NiCr} / \mathrm{Cr}_{3} \mathrm{C}_{2}$ $\mathrm{WS}_{2}$ mixed powders. The microstructure of the coatings consisted of $\alpha-\mathrm{Ti}, \mathrm{TiC}, \mathrm{TiWC} 2, \gamma-\mathrm{NiCrAlTi}, \mathrm{Ti}_{2} \mathrm{CS}$ and $\mathrm{CrS}$ phases. A high temperature tribological study was carried out (at $20,300,600^{\circ} \mathrm{C}$ ) using a ball-on-disc tribometer under dry sliding conditions. Micro-hardness of the coating was almost 3-fold higher; 1,005 HV0.2. The friction coefficient and wear rate were greatly decreased due to combined effect of $\mathrm{TiC}$ and $\mathrm{TiWC}_{2}$ carbides and $\mathrm{CrS}$ and $\mathrm{Ti}_{2} \mathrm{CS}$ sulfides, possessing excellent self-lubricating properties.

Solid lubricant hBN exhibits chemical inertness and oxidation resistance. Similar to graphite, hBN also has a lamellar structure, but exhibits lower friction in high temperature tribological applications (Tomala et al., 2014; Kostoglou et al., 2015; Podgornik et al., 2015). Lu et al. (2016) produced crack and 
pore free Ni60-hBN composite coatings on Ti6Al4V substrate by varying the $\mathrm{hBN}$ content. The coatings had a strong metallurgical bond with the substrate. LMD Ni60 composite coatings were composed of $\mathrm{TiO}_{2}, \gamma-\mathrm{NiCrAlTi}, \mathrm{TiC}$ and $\mathrm{TiB}_{2}$ phases while LMD Ni60-10\%hBN composite coatings consisted of hBN, $\gamma$-NiCrAlTi, TiC and $\mathrm{TiB}_{2}$ phases. The microhardness of the composite coatings with $10 \% \mathrm{hBN}$ was $\sim 1,155$ HV0.2. The tribological testing of the composite coatings were conducted at temperatures $\left(20,300\right.$, and $\left.600^{\circ} \mathrm{C}\right)$ under dry sliding conditions. Ni60-10\%hBN composite coatings exhibited excellent tribological characteristics at high temperatures (300 and $600^{\circ} \mathrm{C}$ ).

Ni-based super alloys with a wide range of alloy compositions are used in various industrial applications over the past four decades in cast, wrought and powder metallurgy forms. Inconel 718 (IN 718) belongs to the group of Ni-based super alloys. Due to the low content of aluminum and titanium, this alloy is known for its good weldability. Therefore, IN 718 is ideally suited for LBAM processes (Strößner et al., 2015).

Jia and Gu (2014) produced IN 718 parts by using SLM at four different energy densities $(\eta)$ 180, 275, 300, and 330 $\mathrm{J} / \mathrm{m}$. The tribological performance was evaluated at room temperature by using a ball-on-disc tribometer. Steel GCr15 ball was used as a counter surface. The coefficient of friction was reported to slightly decrease from 0.62 to 0.58 for SLM parts produced at higher $\eta$. A similar decreasing trend was recorded in the wear rate with increasing $\eta$. The wear performance was indicated to be primarily influenced by micro-hardness and related microstructural features of SLM parts. The lower hardness at lower laser energy density input triggered the higher wear rate due to mechanical shear force between the sliding surfaces. The wear resistance was enhanced at higher laser energy densities, owing to the refined microstructures, as well as improved micro-hardness due to presence of $\gamma^{\prime}$ phase.

$\mathrm{Li}$ et al. (2013) developed self-lubricating Ni-based alloy (Ni-Cr-Mo-Al-10wt.\%Ag-10wt. $\% \mathrm{BaF}_{2} / \mathrm{CaF}_{2}$ ) for a wide range of temperature applications $\left(25-800^{\circ} \mathrm{C}\right)$ by sintering process. It is challenging to design a self-lubricating material for high temperature application without compromising the strength of material. The composite resulted in a remarkable self-lubricity ( $\mu \approx 0.25$ ) and high strength. Similarly Cheng et al. (2017) characterized the NiCrAlMo-12.5wt.\%Ag-X wt.\% $\mathrm{CaF}_{2} / \mathrm{BaF}_{2}$ (X $=5$ or 10 ) solid-lubricating composites by using pin-on-disc configuration for high temperature tribological applications. It was concluded that reducing the fluoride eutectic content leads to the significant improvement in the wear resistance above $600^{\circ} \mathrm{C}$.

Xiao et al. (2018) evaluated the tribological performance of graphene-IN 718 composites produced by SLM. SLM is shown here to be a viable fabrication technique to produce graphene nano-platelets reinforced IN 718. The tribological tests were conducted under ambient condition (temperature of $13 \pm$ $5^{\circ} \mathrm{C}$ and relative humidity of 55-65\%) by using a ball-on-disk WTM-2E tribological tester. The wear counterpart was a GCr15 ball with $3 \mathrm{~mm}$ in diameter. The recorded friction coefficient and wear rate were 22.4 and $66.8 \%$ lower than that of pure IN
718. The decrease in friction coefficient and wear rate were the result of improved hardness due to composite reinforcement and the formation of graphene nano-platelets protective layer on the worn surfaces.

Liu et al. (2013b) investigated self-lubricating LMD coatings of $\mathrm{NiCr}-\mathrm{Cr}_{3} \mathrm{C}_{2}$ with $30 \% \mathrm{WS}_{2}$ and $30 \% \mathrm{WS}_{2}(\mathrm{Ni}-\mathrm{P})$ at 25 , 300 , and $600^{\circ} \mathrm{C}$. Solid lubricant $\mathrm{WS}_{2}$ forms lubricious film in the tribological contacts characterized by a low shear strength and a lamellar structure. $\mathrm{WS}_{2}$ resists oxidation up to $539^{\circ} \mathrm{C}$ and dissolves at higher laser irradiation without encapsulation (Särhammar et al., 2014; Sateesh et al., 2015; Quan et al., 2017). The powder supply for laser processing was preplacing the powder on the substrate. The microstructure of the $\mathrm{NiCr}-$ $\mathrm{Cr}_{3} \mathrm{C}_{2} / 30 \% \mathrm{WS}_{2}$ coating consisted of $\mathrm{Cr}_{7} \mathrm{C}_{3}$ dendrite, $\gamma$ - $(\mathrm{Fe}$, $\mathrm{Ni} / \mathrm{Cr}_{7} \mathrm{C}_{3}$ eutectic and WS2 solid. High temperature tribological tests revealed that $\mathrm{NiCr}-\mathrm{Cr}_{3} \mathrm{C}_{2} / 30 \% \mathrm{WS}_{2}(\mathrm{Ni}-\mathrm{P})$ showed improved performance from room temperature to $600^{\circ} \mathrm{C}$.

Yang et al. (2012) produced wear resistant $\mathrm{NiCr} / \mathrm{Cr}_{3} \mathrm{C}_{2}$ coatings and high temperature self-lubricating wear resistant $\mathrm{NiCr} / \mathrm{Cr}_{3} \mathrm{C}_{2}-30 \%$ WS2 coatings by LMD. Microstructural characterization reveled that $\mathrm{NiCr} / \mathrm{Cr}_{3} \mathrm{C}_{2}$ coatings consisted of $\mathrm{Cr}_{7} \mathrm{C}_{3}$ primary phase and $\gamma-(\mathrm{Fe}, \mathrm{Ni}) / \mathrm{Cr}_{7} \mathrm{C}_{3}$ eutectic colony. The $\mathrm{NiCr} / \mathrm{Cr}_{3} \mathrm{C}_{2}-30 \% \mathrm{WS}_{2}$ coatings consisted of $\mathrm{Cr}$ and $\mathrm{W}$ carbides with minor lubricious phases of $\mathrm{WS}_{2}$ and $\mathrm{CrS}$. The high temperature tribological characterization was performed by using a ball-on-disc tribometer (at 17, 300, and $600^{\circ} \mathrm{C}$ ). The $\mathrm{NiCr} / \mathrm{Cr}_{3} \mathrm{C}_{2}-30 \% \mathrm{WS}_{2}$ coatings showed lower wear till $600^{\circ} \mathrm{C}$ but exhibited higher wear at $600^{\circ} \mathrm{C}$. Laser deposition with the addition of $\mathrm{WS}_{2}$ are considered suitable from room temperature to $300^{\circ} \mathrm{C}$.

Zhao et al. (2019) fabricated self-lubricating wear resistant coatings on stainless steel substrate by combining LMD and vacuum pressure thermal diffusion welding (VPTW). The fabricated coatings consist of separate layers of wear resistant$\mathrm{NiCrSiB}$ and self-lubricating $\mathrm{Cu}$-coated graphite. Microstructure of the wear resistant layers consist of $\gamma$-matrix $(\mathrm{Ni}, \mathrm{Fe})$ and $\mathrm{Cr}$ carbides $\left(\mathrm{Cr}_{7} \mathrm{C}_{3}\right.$ and $\left.\mathrm{Cr}_{23} \mathrm{C}_{6}\right)$ while self-lubricating layers consist of $\mathrm{Cu}$-matrix and graphite. Layers are strongly bonded with each other and the substrate. The tribological properties of the coatings were evaluated at room temperature through reciprocating friction and wear tester Bruker UMT-3. The results indicated better antifriction properties compared to the reference materials (as received substrate, $\mathrm{NiCrSiB}$ and $\mathrm{Cu}-$ graphite coating) due to formation of self-lubricating tribofilm on the wear resistant worn layers. Abrasive wear along with delamination wear were found to be the main wear mechanisms.

\section{EMERGING MATERIALS}

High entropy alloys (HEAs) are a relatively new class of materials, with a novel alloy concept. HEAs are advanced materials with unique properties and such properties cannot be achieved by the conventional micro-alloying approach based on only one dominant element (Zhang et al., 2014). HEAs consist of at least five metal constituents in equi-molar or near equi-molar 
ratios (5-35 at.\%), with face-centered cubic (fcc) and bodycentered cubic (bcc) solid solutions instead of intermetallic and complex brittle phases (Ocelík et al., 2016; Li et al., 2018). HEAs are described as an ideal solution as the configuration entropy of these is equivalent to that of idea gas (Ye et al., 2016), see Figure 8A. A model ternary alloy configuration entropy $\left(\Delta S_{\text {mix }} \mathrm{J} / \mathrm{mol} \cdot \mathrm{K}\right)$ map is shown in Figure $8 \mathrm{~B}$, the alloy composition closer to the center of map reaches to the maximum value.

HEAs are the focus of increasing scientific attention due to enormous possibilities of alloy combinations and the chance of tailoring the constituent elements to achieve the final properties (Brif et al., 2015). Conventionally HEAs are produced by vacuum arc melting (Senkov and Woodward, 2011). HEAs are reported to have excellent mechanical properties and an enhanced high temperature stability (Lu et al., 2015). Senkov et al. (2011) developed two HEAs $\left(\mathrm{Nb}_{25} \mathrm{Mo}_{25} \mathrm{Ta}_{25} \mathrm{~W}_{25}\right.$ and $\mathrm{V}_{20} \mathrm{Nb}_{20} \mathrm{Mo}_{20} \mathrm{Ta}_{20} \mathrm{~W}_{20}$ ) which exhibited yield strength of $\approx 600-800 \mathrm{MPa}\left(\right.$ at $\geq 900^{\circ} \mathrm{C}$ ) exceptionally higher to those of Ni-based super alloys (IN 718 and Haynes 230). Chuang et al. (2011) designed a series of wear resistant HEAs $\left(\mathrm{Al}_{\mathrm{x}} \mathrm{Co}_{1.5} \mathrm{CrFeNi}_{1.5} \mathrm{Ti}_{\mathrm{y}}\right)$ by varying contents of $\mathrm{Al}$ and $\mathrm{Ti}$ and compared with the conventional wear resistant steel alloys (SUJ2 and SKH51) of similar micro-hardness. Wear resistance of HEAs was 2-fold than those of conventional steels due to their excellent resistance to oxidation and thermal softening.

LBAM is one of the new potential production route for HEAs (Popov et al., 2019). Ocelík et al. (2016) attempted to produce the AlCoCrFeNi and AlCrFeNiTa HEAs coatings on stainless steel substrate by using LMD (laser power $\approx 600$ $650 \mathrm{~W})$. It was concluded that LMD is a versatile approach to synthesize HEAs with additive manufacturing processing. However, LMD of HEAs using feeding of mixture of powders is affected by the in-take of particular powders, melting temperatures, laser scan speed and laser power. Zhang et al. (2011) produced 6FeNiCoSiCrAlTi HEA coating with simple bcc solid solution phase on a low carbon steel substrate by using LMD. Microstructural analysis showed the presence of equiaxed polygonal grains, discontinuous interdendritic segregation with bcc structure. The micro-hardness of the coating was 780 HV0.5, much higher than most of the HEAs produced by other fabrication techniques.

Brif et al. (2015) utilized SLM for production of an equiatomic FeCoCrNi HEA. The microstructural and mechanical characterization of SLM parts were performed to investigate the feasibility of producing HEAS in additive manufacturing. Characterization confirmed that SLM fabricated FeCoCrNi HEA preserved its single-phase solid-solution state. Mechanical testing revealed high strength and ductility of FeCoCrNi HEA, comparable to that of stainless steels.

\section{REFERENCES}

Alexeyev, N., and Jahanmir, S. (1993). Mechanics of friction in self-lubricating composite materials I: mechanics of second-phase deformation and motion. Wear 166, 41-48. doi: 10.1016/0043-1648(93)90277-S
Due to the recent development in the concept of HEAs, limited literature on the tribological characterization of HEAs was found. The available data shows the exceptional performance of these alloys at high temperatures. No specific literature was found on tribological performance of LBAM-HEAs. The reported production methods of the tested HEAs were plasma sintering and arc melting (Poletti et al., 2017; Mathiou et al., 2018; Wang et al., 2018; Zhou R. et al., 2018). Zhang et al. (2017a,b) prepared CoCrFeNi HEA matrix self-lubricating composite by $\mathrm{CoCrFeNi}$ HEA powder, nickel-coated graphite powder and nickel-coated $\mathrm{MoS}_{2}$ powder. The method of preparation was spark plasma sintering. The composite exhibited excellent tribological properties from room temperature to $800^{\circ} \mathrm{C}$ when tested in air on a ball-on-disk high temperature tribometer. Synergistic lubricating effect of graphite and $\mathrm{MoS}_{2}$ resulted in the reduction of friction coefficients and wear rates from room temperature to medium temperatures. At high temperatures, various metal oxides were formed on the composite surfaces which improved the tribological properties.

\section{SUMMARY}

This review has presented a comprehensive state-of-art for application-specific material designs followed by LBAM for high temperature tribological applications.

1. Laser-based fabrications of well-designed materials for extreme temperatures have evolved the advanced industrial tribo-systems with multifaceted functionalities, such as higher micro-hardness, thermal stability and self-lubrication (low friction and wear).

2. Among LBAM processes, LMD is extensively employed for fabrication of thick self-lubricating coatings of $\mathrm{Fe}^{-}, \mathrm{Co}^{-}, \mathrm{Ti}^{-}$ and Ni-based alloys. Whereas, SLM has proven to be effective for manufacturing complex 3D geometries of metal-matrix composites (Ni-based super alloys) for high temperature tribological contacts.

3. LBAM materials with the incorporation of appropriate solid lubricants show tremendous potential for high temperature tribology. Solid lubricants like graphite, hBN, TMDs and soft metals (Ag) are used for lubrication at moderate temperatures. TMDs provides encapsulation for soft metals to avoid thermal decomposition during laser-irradiation. Selflubricating materials with lubricious sulfides and oxides are laser-fabricated for extreme temperatures.

\section{AUTHOR CONTRIBUTIONS}

NU and DM were responsible for the final editing. All authors have contributed equally to the content of the final manuscript.

Alman, D. E., Hawk, J. A., and Petrovic, J. J. (1995). Abrasive wear behavior of MoSi2SiC and MoSi2ZrO2 composites. Scr. Metall. Mater. 32, 1765-1770. doi: 10.1016/0956-716X(95)00002-D

Aqida, S. N., Brabazon, D., and Naher, S. (2013). An investigation of phase transformation and crystallinity in laser surface modified 
H13 steel. Appl. Phys. A 110, 673-678. doi: 10.1007/s00339-0127149-2

Bandyopadhyay, A., and Traxel, K. D. (2018). Invited review article: metal-additive manufacturing-modeling strategies for applicationoptimized designs. Addit. Manuf. 22, 758-774. doi: 10.1016/j.addma.2018. 06.024

Belzunce, F., Ziadi, A., and Rodriguez, C. (2004). Structural integrity of hot strip mill rolling rolls. Eng. Fail. Anal. 11, 789-797. doi: 10.1016/j.engfailanal.2003.10.004

Birger, E. M., Moskvitin, G. V., Polyakov, A. N., and Arkhipov, V. E. (2011). Industrial laser cladding: current state and future. Weld. Int. 25, 234-243. doi: 10.1080/09507116.2010.540880

Birol, Y. (2010). High temperature sliding wear behaviour of inconel 617 and stellite 6 alloys. Wear 269, 664-671. doi: 10.1016/j.wear.2010.07.005

Boccalini, M., and Sinatori, A. (2002). "Microstructure and wear resistance of high speed steels for rolling mill rolls," in 6th International Tooling Conference, 425-437.

Brandl, E., Baufeld, B., Leyens, C., and Gault, R. (2010). Additive manufactured Ti6A1-4V using welding wire: comparison of laser and arc beam deposition and evaluation with respect to aerospace material specifications. Phys. Procedia. 5, 595-606. doi: 10.1016/j.phpro.2010.08.087

Brif, Y., Thomas, M., and Todd, I. (2015). The use of high-entropy alloys in additive manufacturing. Scr. Mater. 99, 93-96. doi: 10.1016/j.scriptamat.2014.11.037

Cai, L. X., Wang, C. M., and Wang, H. M. (2003). Laser cladding for wearresistant Cr-alloyed Ni2Si-NiSi intermetallic composite coatings. Mater. Lett. 57, 2914-2918. doi: 10.1016/S0167-577X(02)01396-4

Candel, J. J., Amigó, V., Ramos, J. A., and Busquets, D. (2010). Sliding wear resistance of TiCp reinforced titanium composite coating produced by laser cladding. Surf. Coatings Technol. 204, 3161-3166. doi: 10.1016/j.surfcoat.2010.02.070

Cheng, J., Li, F., Zhu, S., Hao, J., Yang, J., Li, W., et al. (2017). High temperature tribological properties of a nickel-alloy-based solid-lubricating composite: effect of surface tribo-chemistry, counterpart and mechanical properties. Wear 386-387, 39-48. doi: 10.1016/j.wear.2017.06.001

Chuang, M.-H., Tsai, M.-H., Wang, W.-R., Lin, S.-J., and Yeh, J.-W. (2011). Microstructure and wear behavior of AlxCo1.5CrFeNi1.5Tiy high-entropy alloys. Acta Mater. 59, 6308-6317. doi: 10.1016/j.actamat.2011.06.041

Colás, R., Rami'rez, J., Sandoval, I., Morales, J. C., and Leduc, L. A. (1999). Damage in hot rolling work rolls. Wear 230, 56-60. doi: 10.1016/S0043-1648(99)00081-2

Cong, D., Li, Z., He, Q., Chen, D., Chen, H., Yang, J., et al. (2018). Effect of unit size on thermal fatigue behavior of hot work steel repaired by a biomimetic laser remelting process. Opt. Laser. Technol. 98, 205-213. doi: 10.1016/j.optlastec.2017.08.001

DebRoy, T., Wei, H. L., Zuback, J. S., Mukherjee, T., Elmer, J. W., Milewski, J. O., et al. (2018). Additive manufacturing of metallic components - process, structure and properties. Prog. Mater. Sci. 92, 112-224. doi: 10.1016/j.pmatsci.2017.10.001

Deng, G. Y., Zhu, H. T., Tieu, A. K., Su, L. H., Reid, M., Zhang, L., et al. (2017). Theoretical and experimental investigation of thermal and oxidation behaviours of a high speed steel work roll during hot rolling. Int. J. Mech. Sci. 131-132, 811-26. doi: 10.1016/j.ijmecsci.2017.08.024

Ding, D., Pan, Z., Cuiuri, D., and Li, H. (2015). Wire-feed additive manufacturing of metal components: technologies, developments and future interests. Int. J. Adv. Manuf. Technol. 81, 465-481. doi: 10.1007/s00170-015-7077-3

Dobbelstein, H., Gurevich, E. L., George, E. P., Ostendorf, A., and Laplanche, G. (2018). Laser metal deposition of compositionally graded TiZrNbTa refractory high-entropy alloys using elemental powder blends. Addit. Manuf. 25, 252-262. doi: 10.1016/j.addma.2018.10.008

Dohda, K., Boher, C., Rezai-Aria, F., and Mahayotsanun, N. (2015). Tribology in metal forming at elevated temperatures. Friction 3, 1-27. doi: 10.1007/s40544-015-0077-3

d'Oliveira, A. S. C., Vilar, R., and Feder, C. (2002). High temperature behaviour of plasma transferred arc and laser Co-based alloy coatings. Appl. Surf. Sci. 201, 154-160. doi: 10.1016/S0169-4332(02)00621-9

Donnet, C., and Erdemir, A. (2004). Solid lubricant coatings: recent developments and future trends. Tribol. Lett. 17, 389-397. doi: 10.1023/B:TRIL.0000044487.32514.1d
Duan, G., and Wang, H. (2002). High-temperature wear resistance of a laserclad $\gamma / \mathrm{Cr} 3 \mathrm{Si}$ metal silicide composite coating. Scr. Mater. 46, 107-111. doi: 10.1016/S1359-6462(01)01208-8

Erdemir, A. (2000). A crystal-chemical approach to lubrication by solid oxides. Tribol. Lett. 8, 97-102. doi: 10.1023/A:1019183101329

Fedorciuc-Onisa, C., and Farrugia, D. C. J. (2008). Investigations into roll thermal fatigue in hot rolling. Int. J. Mater. Form. 1, 363-366. doi: 10.1007/s12289-008-0070-8

Feng, S -R., Tang, H -B., Zhang, S -Q., and Wang, H -M. (2012). Microstructure and wear resistance of laser clad $\mathrm{TiB}-\mathrm{TiC} / \mathrm{TiNi}-\mathrm{Ti} 2 \mathrm{Ni}$ intermetallic coating on titanium alloy. Trans. Nonferrous. Met. Soc. China 22, 1667-1673. doi: 10.1016/S1003-6326(11)61371-X

Furlan, K. P., de Mello, J. D. B., and Klein, A. N. (2018). Self-lubricating composites containing MoS2: a review. Tribol. Int. 120, 280-298. doi: 10.1016/j.triboint.2017.12.033

Garza-Montes-de-Oca, N. F., Colás, R., and Rainforth, W. M. (2011). On the damage of a work roll grade high speed steel by thermal cycling. Eng. Fail. Anal. 18, 1576-1583. doi: 10.1016/j.engfailanal.2011.06.001

Garza-Montes-de-Oca, N. F., and Rainforth, W. M. (2009). Wear mechanisms experienced by a work roll grade high speed steel under different environmental conditions. Wear 267, 441-448. doi: 10.1016/j.wear.2009. 01.048

Gibson, I., Rosen, D. W., and Stucker, B. (2015). Additive Manufacturing Technologies-3D Printing, Rapid Prototyping, and Direct Digital Manufacturing. New York, NY: Springer-Verlag.

Hardell, J., Hernandez, S., Mozgovoy, S., Pelcastre, L., Courbon, C., and Prakash, B. (2015). Effect of oxide layers and near surface transformations on friction and wear during tool steel and boron steel interaction at high temperatures. Wear 330-331, 223-9. doi: 10.1016/j.wear.2015.02.040

Hashemi, N., Mertens, A., Montrieux, H. M., Tchuindjang, J. T., Dedry, O., Carrus, R., et al. (2017). Oxidative wear behaviour of laser clad high speed steel thick deposits: influence of sliding speed, carbide type and morphology. Surf. Coatings Technol. 315, 519-529. doi: 10.1016/j.surfcoat.2017.02.071

Herzog, D., Seyda, V., Wycisk, E., and Emmelmann, C. (2016). Additive manufacturing of metals. Acta Mater. 117, 371-392. doi: 10.1016/j.actamat.2016.07.019

Holmberg, K., and Matthews, A. (2009). Coatings Tribology: Properties, Mechanisms, Techniques and Applications in Surface Engineering. vol. 53.

Ilo, S., Tomala, A., and Badisch, E. (2011). Oxidative wear kinetics in unlubricated steel sliding contact. Tribol. Int. 44, 1208-1215. doi: 10.1016/j.triboint.2011. 05.021

Jia, Q., and Gu, D. (2014). Selective laser melting additive manufacturing of Inconel 718 superalloy parts: densification, microstructure and properties. J. Alloys Compd. 585, 713-721. doi: 10.1016/j.jallcom.2013.09.171

Kaierle, S., Overmeyer, L., Alfred, I., Rottwinkel, B., Hermsdorf, J., Wesling, V., et al. (2017). Single-crystal turbine blade tip repair by laser cladding and remelting. CIRP J. Manuf. Sci. Technol. 19, 196-199. doi: 10.1016/j.cirpj.2017.04.001

Kashani, H., Amadeh, A., and Ghasemi, H. M. (2007). Room and high temperature wear behaviors of nickel and cobalt base weld overlay coatings on hot forging dies. Wear 262, 800-806. doi: 10.1016/j.wear.2006.08.028

Kathuria, Y. P. (2000). Some aspects of laser surface cladding in the turbine industry. Surf. Coatings Technol. 132, 262-269. doi: 10.1016/S0257-8972(00)00735-0

Kazadi, P., Van Rooyen, C., and Burger, H. (2006). Laser based refurbishment of steel mill components 2006.

Khorasani, A. M., Goldberg, M., Doeven, E. H., and Littlefair, G. (2015). Titanium in biomedical applications-properties and fabrication: a review. J. Biomater. Tissue Eng. 5, 593-619. doi: 10.1166/jbt.2015.1361

Kostoglou, N., Polychronopoulou, K., and Rebholz, C. (2015). Thermal and chemical stability of hexagonal boron nitride (h-BN) nanoplatelets. Vacuum 112, 42-45. doi: 10.1016/j.vacuum.2014.11.009

Lei, Y., Sun, R., Tang, Y., and Niu, W. (2015). Microstructure and phase transformations in laser clad CrxSy/Ni coating on H13 steel. Opt. Lasers Eng. 66, 181-186. doi: 10.1016/j.optlaseng.2014.09.006

Lester, S., Longfield, N., Griffiths, J., Cocker, J., Staudenmaier, C., and Broadhead, G. (2013). New systems for laser cladding. Laser Tech. J. 10, 41-43. doi: 10.1002/latj.201390037 
Leunda, J., Soriano, C., Sanz, C., and Navas, V. G. (2011). Laser cladding of vanadium-carbide tool steels for die repair. Phys. Procedia. 12, 345-352. doi: 10.1016/j.phpro.2011.03.044

Li, F., Cheng, J., Qiao, Z., Ma, J., Zhu, S., Fu, L., et al. (2013). A nickel-alloy-based high-temperature self-lubricating composite with simultaneously superior lubricity and high strength. Tribol. Lett. 49, 573-577. doi: 10.1007/s11249-012-0101-y

Li, G. J., Li, J., and Luo, X. (2015). Effects of post-heat treatment on microstructure and properties of laser cladded composite coatings on titanium alloy substrate. Opt. Laser Technol. 65, 66-75. doi: 10.1016/j.optlastec.2014.07.003

Li, M., Huang, J., Zhu, Y. Y., and Li, Z. G. (2012). Effect of heat input on the microstructure of in-situ synthesized $\mathrm{TiN}-\mathrm{TiB} / \mathrm{Ti}$ based composite coating by laser cladding. Surf. Coatings Technol. 206, 4021-4026. doi: 10.1016/j.surfcoat.2012.03.082

Li, W., Karnati, S., Kriewall, C., Liou, F., Newkirk, J., Brown Taminger, K. M., et al. (2017). Fabrication and characterization of a functionally graded material from Ti-6Al-4V to SS316 by laser metal deposition. Addit. Manuf. 14, 95-104. doi: 10.1016/j.addma.2016.12.006

Li, W., Liaw, P. K., and Gao, Y. (2018). Fracture resistance of high entropy alloys: a review. Intermetallics 99, 69-83. doi: 10.1016/j.intermet.2018.05.013

Liu, X.-B., Liu, H.-Q., Liu, Y.-F., He, X.-M., Sun, C.-F., Wang, M.-D., et al. (2013a). Effects of temperature and normal load on tribological behavior of nickel-based high temperature self-lubricating wear-resistant composite coating. Compos. Part B Eng. 53, 347-354. doi: 10.1016/j.compositesb.2013.05.032

Liu, X.-B., Meng, X.-J., Liu, H.-Q., Shi, G.-L., Wu, S.-H., Sun, C.-F., et al. (2014). Development and characterization of laser clad high temperature selflubricating wear resistant composite coatings on $\mathrm{Ti}-6 \mathrm{Al}-4 \mathrm{~V}$ alloy. Mater. Des. 55, 404-409. doi: 10.1016/j.matdes.2013.09.038

Liu, X.-B., Zheng, C., Liu, Y.-F., Fan, J.-W., Yang, M.-S., He, X.-M., et al. (2013b). A comparative study of laser cladding high temperature wearresistant composite coating with the addition of self-lubricating WS2 and WS2/(Ni-P) encapsulation. J Mater. Process. Technol. 213, 51-58. doi: 10.1016/j.jmatprotec.2012.07.017

Loh, G. H., Pei, E., Harrison, D., and Monzón, M. D. (2018). An overview of functionally graded additive manufacturing. Addit. Manuf. 23, 34-44. doi: 10.1016/j.addma.2018.06.023

Lu, X.-L., Liu, X.-B., Yu, P.-C., Qiao, S.-J., Zhai, Y.-J., Wang, M.-D., et al. (2016). Synthesis and characterization of Ni60-hBN high temperature self-lubricating anti-wear composite coatings on Ti6Al4V alloy by laser cladding. Opt. Laser Technol. 78, 87-94. doi: 10.1016/j.optlastec.2015.10.005

Lu, X. D., and Wang, H. M. (2005). Metallic tribological compatibility of laser clad Mo2Ni3Si/NiSi metal silicide coatings. Surf. Coatings Technol. 200, 2380-2385. doi: 10.1016/j.surfcoat.2004.10.101

Lu, Z. P., Wang, H., Chen, M. W., Baker, I., Yeh, J. W., Liu, C. T., et al. (2015). An assessment on the future development of high-entropy alloys: summary from a recent workshop. Intermetallics 66, 67-76. doi: 10.1016/j.intermet.2015.06.021

Luc, E., Bigerelle, M., Deltombe, R., and Dubar, M. (2015). The representative topography of worn hot rolling mill cylinders. Tribol. Int. 82, 387-399. doi: 10.1016/j.triboint.2014.05.031

Mathiou, C., Poulia, A., Georgatis, E., and Karantzalis, A. E. (2018). Microstructural features and dry-sliding wear response of MoTaNbZrTi high entropy alloy. Mater. Chem. Phys. 210, 126-135. doi: 10.1016/j.matchemphys.2017.08.036

Matthews, A., Franklin, S., and Holmberg, K. (2007). Tribological coatings: contact mechanisms and selection. J. Phys. D Appl. Phys. 40, 5463-5475. doi: 10.1088/0022-3727/40/18/S07

Mayrhofer, P. H., Mitterer, C., Hultman, L., and Clemens, H. (2006). Microstructural design of hard coatings. Prog. Mater. Sci. 51, 1032-1114. doi: 10.1016/j.pmatsci.2006.02.002

Murr, L. E., Quinones, S. A., Gaytan, S. M., Lopez, M. I., Rodela, A., Martinez, E. Y., et al. (2009). Microstructure and mechanical behavior of Ti-6Al-4V produced by rapid-layer manufacturing, for biomedical applications. J. Mech. Behav. Biomed. Mater. 2, 20-32. doi: 10.1016/j.jmbbm.2008.05.004

Navas, C., Cadenas, M., Cuetos, J. M., and de Damborenea, J. (2006). Microstructure and sliding wear behaviour of Tribaloy T800 coatings deposited by laser cladding. Wear 260, 838-846. doi: 10.1016/j.wear.2005.04.020
Newkirk, J., and Hawk, J. (2001). Abrasive wear properties of Cr-Cr3Si composites. Wear 251, 1361-1371. doi: 10.1016/S0043-1648(01)00768-2

Nilsson, M., and Olsson, M. (2013a). Microstructural, mechanical and tribological characterisation of roll materials for the finishing stands of the hot strip mill for steel rolling. Wear 307, 209-217. doi: 10.1016/j.wear.2013. 09.002

Nilsson, M., and Olsson, M. (2013b). An investigation of worn work roll materials used in the finishing stands of the hot strip mill for steel rolling. Proc. Inst. Mech. Eng. Part J. J. Eng. Tribol. 227, 837-844. doi: 10.1177/13506501134 78333

Ocelík, V., and De Hosson, J. T. M. (2018). Thick metallic coatings produced by coaxial and side laser cladding: processing and properties. Adv. Laser Mater. Process 2018, 413-459. doi: 10.1016/B978-0-08-101252-9.00015-7

Ocelík, V., Janssen, N., Smith, S. N., and De Hosson, J. T. M. (2016). Additive manufacturing of high-entropy alloys by laser processing. Jom 68, 1810-1818. doi: 10.1007/s11837-016-1888-z

Ocelík, V., Matthews, D., and De Hosson, J. T. M. (2005). Sliding wear resistance of metal matrix composite layers prepared by high power laser. Surf. Coatings Technol. 197, 303-315. doi: 10.1016/j.surfcoat.2004.09.003

Parry, L., Ashcroft, I. A., and Wildman, R. D. (2016). Understanding the effect of laser scan strategy on residual stress in selective laser melting through thermo-mechanical simulation. Addit. Manuf. 12, 1-15. doi: 10.1016/j.addma.2016.05.014

Pellizzari, M., Cescato, D., and De Flora, M. G. (2009). Hot friction and wear behaviour of high speed steel and high chromium iron for rolls. Wear 267, 467-475. doi: 10.1016/j.wear.2009.01.049

Pellizzari, M., Molinari, A., and Straffelini, G. (2005). Tribological behaviour of hot rolling rolls. Wear 259, 1281-1289. doi: 10.1016/j.wear.2004.12.006

Podgornik, B., Kosec, T., Kocijan, A., and Donik, C. (2015). Tribological behaviour and lubrication performance of hexagonal boron nitride (h-BN) as a replacement for graphite in aluminium forming. Tribol. Int. 81, 267-275. doi: 10.1016/j.triboint.2014.09.011

Poletti, M. G., Fiore, G., Gili, F., Mangherini, D., and Battezzati, L. (2017). Development of a new high entropy alloy for wear resistance: FeCoCrNiW0.3 and FeCoCrNiW0.3 + 5 at.\% of C. Mater. Des. 115, 247-254. doi: 10.1016/j.matdes.2016.11.027

Popov, V. V., Katz-Demyanetz, A., Koptyug, A., and Bamberger, M. (2019). Selective electron beam melting of Al0.5CrMoNbTa0.5 high entropy alloys using elemental powder blend. Heliyon 5:e01188. doi: 10.1016/j.heliyon.2019.e01188

Pusavec, F., Hamdi, H., Kopac, J., and Jawahir, I. S. (2011). Surface integrity in cryogenic machining of nickel based alloy-Inconel 718 . J. Mater. Process Technol. 211, 773-783. doi: 10.1016/j.jmatprotec.2010. 12.013

Quan, X., Zhang, S., Hu, M., Gao, X., Jiang, D., and Sun, J. (2017). Tribological properties of WS2/MoS2-Ag composite films lubricated with ionic liquids under vacuum conditions. Tribol. Int. 115, 389-396. doi: 10.1016/j.triboint.2017.06.002

Quazi, M. M., Fazal, M. A., Haseeb, A. S. M. A., Yusof, F., Masjuki, H. H., and Arslan, A. (2016). A review to the laser cladding of selflubricating composite coatings. Lasers Manuf. Mater. Process 3, 67-99. doi: 10.1007/s40516-016-0025-8

Rahman, M. S., Ding, J., Beheshti, A., Zhang, X., and Polycarpou, A. A. (2018). Elevated temperature tribology of $\mathrm{Ni}$ alloys under helium environment for nuclear reactor applications. Tribol. Int. 123, 372-384. doi: 10.1016/j.triboint.2018.03.021

Ray, A., Arora, K. S., Lester, S., and Shome, M. (2014). Laser cladding of continuous caster lateral rolls: microstructure, wear and corrosion characterisation and on-field performance evaluation. J. Mater. Process Technol. 214, 1566-1575. doi: 10.1016/j.jmatprotec.2014.02.027

Rynio, C., Hattendorf, H., Klöwer, J., and Eggeler, G. (2014). The evolution of tribolayers during high temperature sliding wear. Wear 315, 1-10. doi: 10.1016/j.wear.2014.03.007

Sanz, A. (2004). New coatings for continuous casting rolls. Surf. Coatings Technol. 177-178, 1-11. doi: 10.1016/j.surfcoat.2003.06.024

Särhammar, E., Strandberg, E., Sundberg, J., Nyberg, H., Kubart, T., Jacobson, S., et al. (2014). Mechanisms for compositional variations of coatings 
sputtered from a WS2 target. Surf. Coatings Technol. 252, 186-190. doi: 10.1016/j.surfcoat.2014.04.066

Sateesh, N. H., Kumar, G. C. M., and Krishna, P. (2015). Influence of Ni-P coated $\mathrm{SiC}$ and laser scan speed on the microstructure and mechanical properties of IN625 metal matrix composites. Lasers Manuf. Mater. Process 2, 187-198. doi: $10.1007 / \mathrm{s} 40516-015-0014-3$

Scharf, T. W., and Prasad, S. V. (2013). Solid lubricants: a review. J. Mater. Sci. 48, 511-531. doi: 10.1007/s10853-012-7038-2

Schopphoven, T., Gasser, A., Wissenbach, K., and Poprawe, R. (2016). Investigations on ultra-high-speed laser material deposition as alternative for hard chrome plating and thermal spraying. J. Laser Appl. 28, 022501-022509. doi: $10.2351 / 1.4943910$

Semenov, A. P. (1995). Tribology at high temperatures. Tribol. Int. 28, 45-50. doi: 10.1016/0301-679X(95)99493-5

Senkov, O. N., Wilks, G. B., Scott, J. M., and Miracle, D. B. (2011). Mechanical properties of Nb25Mo25Ta25W25 and V20Nb20Mo20Ta20W20 refractory high entropy alloys. Intermetallics 19, 698-706. doi: 10.1016/j.intermet.2011.01.004

Senkov, O. N., and Woodward, C. F. (2011). Microstructure and properties of a refractory NbCrMo0.5Ta0.5TiZr alloy. Mater. Sci. Eng. A 529, 311-320. doi: 10.1016/j.msea.2011.09.033

Sexton, L., Lavin, S., Byrne, G., and Kennedy, A. (2002). Laser cladding of aerospace materials. J. Mater. Proc. Technol. 122, 63-68. doi: 10.1016/S0924-0136(01)01121-9

Sheng, W., Liu, D., and Wang, H. M. (2008). Microstructure and high-temperature wear behavior of laser clad Ni-Ti-Si ternary metal silicide coatings. Surf. Coatings Technol. 202, 2871-2877. doi: 10.1016/j.surfcoat.2007.10.029

Singh, S., Ramakrishna, S., and Singh, R. (2017). Material issues in additive manufacturing : a review. J. Manuf. Process. 25, 185-200. doi: 10.1016/j.jmapro.2016.11.006

Song, J., Valefi, M., de Rooij, M., and Schipper, D. J. (2010). A mechanical model for surface layer formation on self-lubricating ceramic composites. Wear 268, 1072-1079. doi: 10.1016/j.wear.2010.01.012

Strößner, J., Terock, M., and Glatzel, U. (2015). Mechanical and microstructural investigation of nickel-based superalloy IN718 manufactured by selective laser melting (SLM). Adv. Eng. Mater. 17, 1099-1105. doi: 10.1002/adem.2015 00158

Sun, G. F., Yao, S., Wang, Z. D., Shen, X. T., Yan, Y., Zhou, R., et al. (2018). Microstructure and mechanical properties of HSLA-100 steel repaired by laser metal deposition. Surf. Coatings Technol. 351, 198-211. doi: 10.1016/j.surfcoat.2018.07.048

Szost, B. A., Terzi, S., Martina, F., Boisselier, D., Prytuliak, A., Pirling, T., et al. (2016). A comparative study of additive manufacturing techniques: residual stress and microstructural analysis of CLAD and WAAM printed Ti-6Al-4V components. Mater. Des. 89, 559-67. doi: 10.1016/j.matdes.2015. 09.115

Thompson, S. M., Bian, L., Shamsaei, N., and Yadollahi, A. (2015). An overview of direct laser deposition for additive manufacturing; part I: transport phenomena, modeling and diagnostics. Addit. Manuf. 8, 36-62. doi: 10.1016/j.addma.2015.07.001

Tobar, M. J., Amado, J. M., Álvarez, C., García A, Varela, A., and Yáñez, A. (2008). Characteristics of tribaloy T- 800 and T-900 coatings on steel substrates by laser cladding. Surf. Coatings Technol. 202, 2297-2301. doi: 10.1016/j.surfcoat.2007. 11.025

Tomala, A., Hernandez, S., Rodriguez Ripoll, M., Badisch, E., and Prakash, B. (2014). Tribological performance of some solid lubricants for hot forming through laboratory simulative tests. Tribol. Int. 74, 164-173. doi: 10.1016/j.triboint.2014.02.008

Torres, H., Ripoll, M. R., and Prakash, B. (2017). Tribological behaviour of self-lubricating materials at high temperatures. Int. Mater. Rev. 63, 309-340. doi: 10.1080/09506608.2017.1410944

Torres, H., Slawik, S., Gachot, C., Prakash, B., and Rodríguez Ripoll, M. (2018a). Microstructural design of self-lubricating laser claddings for use in high temperature sliding applications. Surf. Coatings Technol. 337, 24-34. doi: 10.1016/j.surfcoat.2017.12.060

Torres, H., Varga, M., Adam, K., and Rodríguez Ripoll, M. (2016b). The role of load on wear mechanisms in high temperature sliding contacts. Wear 364-365, 73-83. doi: 10.1016/j.wear.2016.06.025
Torres, H., Varga, M., Widder, F., Cihak-Bayr, U., Viskovic, O., and Rodríguez Ripoll, M. (2016a). Experimental simulation of high temperature sliding contact of hot rolled steel. Tribol. Int. 93, 745-754. doi: 10.1016/j.triboint.2015.01.007

Torres, H., Vuchkov, T., Rodríguez Ripoll, M., and Prakash, B. (2018b). Tribological behaviour of MoS2-based self-lubricating laser cladding for use in high temperature applications. Tribol. Int. 126, 153-165. doi: 10.1016/j.triboint.2018.05.015

Torres, H., Vuchkov, T., Slawik, S., Gachot, C., Prakash, B., and Rodríguez Ripoll, M. (2018c). Self-lubricating laser claddings for reducing friction and wear from room temperature to $600^{\circ} \mathrm{C}$. Wear $408-409,22-33$. doi: 10.1016/j.wear.2018.05.001

Trosch, T., Strößner, J., Völkl, R., and Glatzel, U. (2016). Microstructure and mechanical properties of selective laser melted inconel 718 compared to forging and casting. Mater. Lett. 164, 428-431. doi: 10.1016/j.matlet.2015. 10.136

Tuominen, J., Näkki, J., Pajukoski, H., Hyvärinen, L., and Vuoristo, P. (2016). Microstructural and abrasion wear characteristics of laser-clad tool steel coatings. Surf. Eng. 32, 923-933. doi: 10.1080/02670844.2016.11 80496

Ulutan, D., and Ozel, T. (2011). Machining induced surface integrity in titanium and nickel alloys: a review. Int. J. Mach. Tools. Manuf. 51, 250-280. doi: 10.1016/j.ijmachtools.2010.11.003

Ur Rahman, N., Capuano, L., Rooij, M. B., de, Matthews, D. T. A., Garcia-Junceda, A., Mekicha, M. A., et al. (2019b). Laser metal deposition of vanadium-rich high speed steel microstructural and high temperature wear characterization. Surf. Coatings Technol. 364, 115-126. doi: 10.1016/j.surfcoat.2019. 02.044

Ur Rahman, N., Capuano, L., van der Meer, A., de Rooij, M. B., Matthews, D. T. A., Walmag, G., et al. (2018). Development and characterization of multilayer laser cladded high speed steels. Addit. Manuf. 24, 76-85. doi: 10.1016/j.addma.2018.09.009

Ur Rahman, N., De Rooij, M. B., Matthews, D. T. A., Walmag, G., Sinnaeve, M., and Römer, G. (2019a). Wear characterization of multilayer laser cladded high speed steels ? Tribol. Int. 130, 52-62. doi: 10.1016/j.triboint.2018. 08.019

Wan, S., Tieu, A. K., Xia, Y., Zhu, H., Tran, B. H., and Cui, S. (2016). An overview of inorganic polymer as potential lubricant additive for high temperature tribology. Tribol. Int. 102, 620-635. doi: 10.1016/j.triboint.2016.06.010

Wang, C., and $\mathrm{Ku}, \mathrm{S}$. (2009). Novel conversion matrices for simplifying the IFFT computation of an. IEEE Trans. Commun. 57, 1903-1907. doi: 10.1109/TCOMM.2009.07.070156

Wang, H. M., and Duan, G. (2002). Microstructure and wear resistance of a laser clad reinforced Cr3Si metal silicide composite coating. Mater. Sci. Eng. A 336, 117-123. doi: 10.1016/S0921-5093(01)01970-0

Wang, H. M., Wang, C. M., and Cai, L. X. (2003). Wear and corrosion resistance of laser clad Ni2Si/NiSi composite coatings. Surf. Coatings Technol. 168, 202-208. doi: 10.1016/S0257-8972(03)00240-8

Wang, J., Guo, T., Li, J., Jia, W., and Kou, H. (2018). Microstructure and mechanical properties of non-equilibrium solidified CoCrFeNi high entropy alloy. Mater. Chem. Phys. 210, 192-196. doi: 10.1016/j.matchemphys.2017.06.037

Wang, S. H., Chen, J. Y., and Xue, L. (2006). A study of the abrasive wear behaviour of laser-clad tool steel coatings. Surf. Coatings Technol. 200, 3446-3458. doi: 10.1016/j.surfcoat.2004.10.125

Wei, D. B., Huang, J. X., Zhang, A. W., Jiang, Z. Y., Tieu, A. K., Shi, X., et al. (2011). The effect of oxide scale of stainless steels on friction and surface roughness in hot rolling. Wear 271, 2417-2425. doi: 10.1016/j.wear.2010.11.029

Weng, F., Yu, H., Chen, C., Liu, J., and Zhao, L. (2015). Microstructures and properties of TiN reinforced Co-based composite coatings modified with Y2O3 by laser cladding on Ti-6Al-4V alloy. J. Alloys Compd. 650, 178-184. doi: 10.1016/j.jallcom.2015.07.295

Xiao, W -H., Lu, S -Q., Wang, Y -C., and Shi, J. (2018). Mechanical and tribological behaviors of graphene/Inconel 718 composites. Trans. Nonferrous Met. Soc. China 28, 1958-1969. doi: 10.1016/S1003-6326(18)64841-1

Ya, W., Pathiraj, B., Matthews, D. T. A., Bright, M., and Melzer, S. (2018). Cladding of tribaloy T400 on steel substrates using a high power Nd:YAG laser. Surf. Coatings Technol. 350, 323-333. doi: 10.1016/j.surfcoat.2018.06.069 
Yamada, M. (1996). An overview on the development of titanium alloys for non-aerospace application in Japan. Mater. Sci. Eng. A 213, 8-15. doi: 10.1016/0921-5093(96)10241-0

Yang, M.-S., Liu, X.-B., Fan, J.-W., He, X.-M., Shi, S.-H., Fu, G. Y., et al. (2012). Microstructure and wear behaviors of laser clad NiCr/Cr3C2-WS2 high temperature self-lubricating wear-resistant composite coating. Appl. Surf. Sci. 258, 3757-3762. doi: 10.1016/j.apsusc.2011.12.021

Yang, Y. (1999). Microstructure and properties of laser-clad hightemperature wear-resistant alloys. Appl. Surf. Sci. 140, 19-23. doi: 10.1016/S0169-4332(98)00320-1

Yao, J., Ding, Y., Liu, R., Zhang, Q., and Wang, L. (2018). Wear and corrosion performance of laser-clad low-carbon high-molybdenum Stellite alloys. Opt. Laser Technol. 107, 32-45. doi: 10.1016/j.optlastec.2018. 05.021

Yao, M. X., Wu, J. B. C., and Liu, R. (2005). Microstructural characteristics and corrosion resistance in molten $\mathrm{Zn}-\mathrm{Al}$ bath of $\mathrm{Co}-\mathrm{Mo}-\mathrm{Cr}-\mathrm{Si}$ alloys. Mater. Sci. Eng. A 407, 299-305. doi: 10.1016/j.msea.2005. 07.054

Yao, M. X., Wu, J. B. C., Yick, S., Xie, Y., and Liu, R. (2006). High temperature wear and corrosion resistance of a laves phase strengthened $\mathrm{Co}-\mathrm{Mo}-\mathrm{Cr}-\mathrm{Si}$ alloy. Mater. Sci. Eng. A 435-436, 78-83. doi: 10.1016/j.msea.2006.07.054

Yap, C. Y., Chua, C. K., Dong, Z. L., Liu, Z. H., Zhang, D. Q., Loh, L. E., et al. (2015). Review of selective laser melting: materials and applications. Appl. Phys. Rev. 2:041101. doi: 10.1063/1.4935926

Ye, Y. F., Wang, Q., Lu, J., Liu, C. T., and Yang, Y. (2016). Highentropy alloy: challenges and prospects. Mater Today. 19, 349-362. doi: 10.1016/j.mattod.2015.11.026

Zhai, Y.-J., Liu, X.-B., Qiao, S.-J., Wang, M.-D., Lu, X.-L., Wang, Y.-G., et al. (2017). Characteristics of laser clad $\alpha$-Ti/TiC+(Ti,W)C1-x/Ti2SC+TiS composite coatings on TA2 titanium alloy. Opt. Laser Technol. 89, 97-107. doi: 10.1016/j.optlastec.2016.09.044

Zhang, A., Han, J., Su, B., Li, P., and Meng, J. (2017a). Microstructure, mechanical properties and tribological performance of $\mathrm{CoCrFeNi}$ high entropy alloy matrix self-lubricating composite. Mater. Des. 114, 253-263. doi: 10.1016/j.matdes.2016.11.072
Zhang, A., Han, J., Su, B., and Meng, J. (2017b). A novel CoCrFeNi high entropy alloy matrix self-lubricating composite. J. Alloys Compd. 725, 700-710. doi: 10.1016/j.jallcom.2017.07.197

Zhang, H., Pan, Y., He, Y., and Jiao, H. (2011). Microstructure and properties of 6FeNiCoSiCrAlTi high-entropy alloy coating prepared by laser cladding. Appl. Surf. Sci. 257, 2259-2263. doi: 10.1016/j.apsusc.2010.09.084

Zhang, Y., Zuo, T. T., Tang, Z., Gao, M. C., Dahmen, K. A., Liaw, P. K., et al. (2014). Microstructures and properties of high-entropy alloys. Prog. Mater. Sci. 61, 1-93. doi: 10.1016/j.pmatsci.2013.10.001

Zhao, H., Liu, Y., Xu, B., Lu, Y., Zhou, C., Wu, X., et al. (2019). Fabrication and tribological properties of a self-lubricating wearresistant coating based on structural coupling. Ceram Int. 45, 3910-3920. doi: 10.1016/j.ceramint.2018.11.064

Zhou, R., Chen, G., Liu, B., Wang, J., Han, L., and Liu, Y. (2018). Microstructures and wear behaviour of (FeCoCrNi)1-x(WC)x high entropy alloy composites. Int. J. Refract. Met. Hard Mater. 75, 56-62. doi: 10.1016/j.ijrmhm.2018.03.019

Zhou, Y. H., Zhang, Z. H., Wang, Y. P., Liu, G., Zhou, S. Y., Li, Y. L., et al. (2018). Selective laser melting of typical metallic materials: an effective process prediction model developed by energy absorption and consumption analysis. Addit Manuf. 25, 204-217. doi: 10.1016/j.addma.2018.10.046

Zhu, D., Zhang, X., and Ding, H. (2013). Tool wear characteristics in machining of nickel-based superalloys. Int. J. Mach. Tools. Manuf. 64, 60-77. doi: 10.1016/j.ijmachtools.2012.08.001

Conflict of Interest Statement: The authors declare that the research was conducted in the absence of any commercial or financial relationships that could be construed as a potential conflict of interest.

Copyright (c) 2019 Ur Rahman, Matthews, de Rooij, Khorasani, Gibson, Cordova and Römer. This is an open-access article distributed under the terms of the Creative Commons Attribution License (CC BY). The use, distribution or reproduction in other forums is permitted, provided the original author(s) and the copyright owner(s) are credited and that the original publication in this journal is cited, in accordance with accepted academic practice. No use, distribution or reproduction is permitted which does not comply with these terms. 